Ecological Economics

November 2015, Volume 119 Pages 39-52

http://dx.doi.org/10.1016/j.ecolecon.2015.02.005

http://archimer.ifremer.fr/doc/00276/38732/

(c) 2015 Published by Elsevier B.V.

\title{
Ecoviability for small-scale fisheries in the context of food security constraints
}

\author{
Cisse A. ${ }^{2,{ }^{*}}$, Doyen L. ${ }^{3}$, Blanchard Fabian ${ }^{1}$, Béné Christophe ${ }^{4}$, Péreau J.-C. ${ }^{3}$
}

${ }^{1}$ IFREMER, Domaine de Suzini, BP 477, 97331 Cayenne, French Guiana, France

${ }^{2}$ CEREGMIA, University of French West Indies and Guiana, 2091 route de Baduel, BP 266, 97326

Cayenne, French Guiana, France

${ }^{3}$ GRETHA, CNRS, University of Bordeaux, Avenue Léon Duguit, 33608 Pessac, France

${ }^{4}$ Institute of Development Studies, University of Sussex, Brighton, UK

*Corresponding autor : A. Cissé, email address : cisse.ahad@hotmail.com

\begin{abstract}
:
This paper applies a stochastic viability approach to a tropical small-scale fishery, offering a theoretical and empirical example of ecosystem-based fishery management approach that accounts for food security. The model integrates multi-species, multi-fleet and uncertainty as well as profitability, food production, and demographic growth. It is calibrated over the period 2006-2010 using monthly catch and effort data from the French Guiana's coastal fishery, involving thirteen species and four fleets. Using projections at the horizon 2040, different management strategies and scenarios are compared from a viability viewpoint, thus accounting for biodiversity preservation, fleet profitability and food security. The analysis shows that under certain conditions, viable options can be identified which allow fishing intensity and production to be increased to respond to food security requirements but with minimum impacts on the marine resources.
\end{abstract}

Keywords : Small-scale fishery, Biodiversity, Sustainability, Profitability, Food security, Multi-species, Multi-fleet, Stochasticity, Viability, Scenario 


\section{Introduction}

Reconciling food security with biodiversity protection is among the greatest challenges of the century, especially in the face of demographic transition (Godfray et al., 2010; Rice and Garcia, 2011). The case of fisheries and marine ecosystems is especially challenging in that regard. Marine and coastal ecosystems are experiencing accelerating changes in their populations, species and communities at different biotic scales, with some alarming trends (extinctions, depletion, ...) and largely unknown consequences (Myers and Worm, 2003; Millennium Ecosystem Assessment, 2005; Butchart and Walpole, 2010). Part of the degradation in biodiversity is due to fishing pressure, through processes such as overexploitation and "fishing down the food chain" (Ye et al., 2012). These changes in marine biodiversity in turn impact ecosystem services, including food production capacities and fishing activities as emphasized by the current stagnation or decline of global catches despite continuous increasing fishing efforts (FAO, 2012). These trends raise key concerns in relation to food security, especially for developing countries with high demographic pressure. In this perspective, the sustainable management of tropical small-scale fisheries is a key issue (Garcia et al., 2008). However the conventional approaches for operationalizing sustainability based on MSY ${ }^{1}$, MEY or the ICES ${ }^{2}$ precautionary approach, were globally unable to prevent over-exploitation and fishing overcapacity worldwide (Hall and Mainprize, 2004; Hilborn, 2011) . By considering each exploited species separately (Grafton et al., 2007), these approaches often fail to account for the multi-species and multi-fleet interactions which play an important role in fish mortality and fleet profitability. The account for such a bio-economic complexity is especially crucial for small-scale fisheries usually characterized by non-selective fishing vessels.

The need for Ecosystem-Based Fisheries Management (EBFM) advocating an integrated management of marine resources is now widely accepted (Garcia et al., 2003). Such a multi-objective framework first requires to account for the complexity of ecological mechanisms that encompass community dynamics, trophic webs, geographical processes and environmental uncertainties (habitat, climate). Furthermore, by putting emphasis on sustainability, this approach strives to balance ecological and economic objectives for present and future generations and to handle a large range

\footnotetext{
${ }^{1} \mathrm{MSY}=$ Maximum Sustainable Yield; MEY $=$ Maximum Economic Yield

${ }^{2}$ International Council for the Exploration of the Sea: http://www.ices.dk.
} 
of goods and services provided by marine ecosystems (Garcia et al., 2008; Jennings, 2005), including both monetary and non-monetary values. However, implementing such an approach remains challenging (Sanchirico et al., 2008; Doyen et al., 2013). It requires models, indicators, reference points and adaptive management strategies (King and Mcfarlane, 2006). Plaganyi (2007) provides an overview of the main types of modeling approaches and analyzes their relative merits and limitations for fisheries assessment in an ecosystem context. Modeling approaches and metrics useful for planning, implementing, and evaluating EBFM are also discussed in Marasco et al. (2007), with particular emphasis on management strategy evaluation. An overview of recent developments in robust optimization can be found in Gabrel et al. (2014). The use of ecosystem indicators is analyzed by Rice (2000) and Cury and Christensen (2005).

The present paper proposes to use a bio-economic viability framework as a methodological tool to explore, through modeling and scenarios, the implementation of the EBFM in the case of smallscale fisheries facing food security constraints. Viability modeling is now recognized by a growing number of scholars - e.g. Cury et al. (2005); Doyen et al. (2007); De Lara et al. (2012); Péreau et al. (2012); Cissé et al. (2013); Thébaud et al. (2014) - as a relevant framework for EBFM. Viability theory strives to identify 'viable' paths that ensure the simultaneous fulfillment of several desirable objectives over time (Béné et al., 2001). These objectives, represented through a series of constraints that need to be satisfied throughout time, capture the multi-dimensional nature of sustainability (Doyen and Martinet, 2012). Furthermore, because it takes into account uncertainties, stochastic viability approach appears to be a relevant framework to ensure robust alternative management (Baumgartner and Quaas, 2009; Doyen et al., 2012; Gourguet et al., 2013). Finally Cissé et al. (2013) and Hardy et al. (2013) recently showed how the viability approach can also provide useful insights in tropical fisheries operating under demographic pressure.

In that context, the coastal fishery in French Guiana provides a very relevant case-study to apply the EBFM together with stochastic viability. This fishery is characterized by various complex features including a high equatorial fish biodiversity impacted by several non-selective fleets and a strong demographic pressure, which eventually is likely to affect the productivity of the fishery and its contribution to local food security.

The contributions of this article are numerous. Firstly, by involving prospective scenarios (forward-looking), this paper presents an approach for stochastic viability. By using feedback 
controls in uncertain context, it reinforces the adaptiveness of fishery regulation. Secondly, this work proposes to tackle the issue of food security for the management of the French Guiana coastal fishery. Lastly, by accounting for complex and non-linear dynamics within a trophic multi-fleet context and by addressing biodiversity issues, the paper confirms that stochastic viability modeling can be applied to high dimensional environmental systems.

\section{Case study}

French Guiana is a French Overseas Territory located in South America between Brazil and Suriname. It has a 350-km coastline and an exclusive economic zone (EEZ) of 130,000 km², which includes 50,000 $\mathrm{km}^{2}$ of continental shelf. The small-scale coastal fishery, with landing points spread along the coast, operates up to $16 \mathrm{~km}$ offshore at depths of 0-20 $\mathrm{m}$. This multi-species fishery exploits more than 30 species (weakfish, catfish, shark, grouper, etc.) and around 3000 tons are landed annually worth $€ 9$ millions. In terms of volume the most important species include the Acoupa weakfish, the Crucifix sea catfish and Green weakfish representing $65 \%$ of the annual catches. This fishery is also multi-fleet: the 200 wooden boats include four different types of vessels: canots créoles $(\mathrm{CC})$, canots créoles améliorés $(\mathrm{CCA})$, pirogues $(\mathrm{P})$ and tapouilles $(\mathrm{T})$. These four groups of boat differ from each other by the type of engine, type of fishing gear, number of fishers onboard, number of days spent at sea and fishing grounds, thus entailing various catchability and cost parameters. As an EU overseas region, French Guiana coastal fishery is managed under the French and the European legislations through technical measures (maximum net length, minimum mesh size and marine protected area) and access regulation (European and regional licenses). The conditions associated with these management tools are not derived from particular stock assessments, they were essentially set up to preserve the current status quo.

Since 2006, Ifremer ${ }^{3}$ has been implementing a monitoring system covering all the vessels operating in the fishery. At each landing site, observers from local communities record on a daily basis the catches (by species), the number of crew on board, the fishing area, trip duration, gear used and quantity of fuel and ice consumed by the boats. The socio-economic assessment of the sector informs on production costs, selling prices, fishers living condition and education level.

\footnotetext{
${ }^{3}$ French Research Institute for Exploitation of the Sea.
} 
Currently, the ecological status of the fishery is considered to be healthy, and the biodiversity associated with the resource does not seem to be threatened by fishing activity. No particular negative trend is observed in the catch or in the catch per unit of effort ${ }^{4}$ of the main species and the latest 2010 economic assessment shows that the fishery is profitable even if it is strongly sensitive to the fuel price and the fish selling prices (Cissé et al., 2014). On the demand side, the production is essentially directed to the local consumption. Demographic projections suggest however a $100 \%$ increase of the local population over the next 20 years. The question arises therefore on whether the marine ecosystem and the fishing sector will be able to cope with the predicted increase in demand and continue to fulfill their food security function without a detrimental effect for the resource. Let us add that this food security constraint cannot be satisfied with other domestic sectors as the agricultural sector for instance.

To examine these issues, this paper proposes to use a bio-economic model which includes multispecies and multi-fleet dynamics based on Lotka-Volterra trophic interactions and that accounts for uncertainty on species growth. The model is calibrated for thirteen species and four fleets using the monthly catch and effort data derived from the Ifremer fishery monitoring system from 2006 to 2010. Scenarios including status quo, maximization of the net present value, and viability strategies are examined and compared. The model aims at improving the knowledge of the French Guiana coastal fishery and at ensuring its future sustainable management relying on an ecosystem based approach.

The paper is structured as follows. Section 3 describes the ecosystem-based model together with the relevant bio-economic indicators and scenarios. Section 4 presents the results of the different fishing scenarios while section 5 discusses those results in relation to sustainability, EBFM and more general fisheries management tools.

\section{Methods}

\subsection{The ecosystem-based model}

The stylized bio-economic model, inspired by Cissé et al. (2013), relies on a Lotka-Volterra preypredator dynamics with $n=14$ species (Table 1 ) and $m=4$ fleets exploiting them as displayed

\footnotetext{
${ }^{4}$ This variable is traditionally used in fisheries literature as a proxy for biomass.
} 
in Figure 1. The thirteen selected species contribute around $90 \%$ of the annual landings from 2006 to 2010 while a virtual fourteenth species is introduced in the model to capture all the other stocks of the ecosystem. The model is described in discrete time with a monthly step and accounts for uncertainties in species growth. It is assumed that harvesting takes place at the beginning of the period $t$ while regeneration and trophic processes occur at the end. Thus, at each step $t$, the biomass $B_{i}(t+1)(\mathrm{kg})$ of species $i$ at time $t+1$, after harvesting $H_{i}(t)$, depends on other stocks $B_{j}(t)$ and an uncertainty parameter $\epsilon(t)$ through eqs(1)-(3):

$$
B_{i}(t+1)=g_{i}\left(B(t)-H(t), \epsilon_{i}(t)\right)
$$

with

$$
\begin{gathered}
g_{i}\left(B_{1}, \ldots, B_{n}, \epsilon_{i}\right)=B_{i} \cdot\left(1+r_{i}-\frac{r_{i}}{K_{i}} B_{i}+\sum_{j \neq i} s_{i, j} B_{j}+\epsilon_{i}\right), \\
H_{i}(t)=\sum_{f=1}^{m} H_{i, f}(t)=\sum_{f=1}^{m} q_{i, f} e_{f}(t) B_{i}(t) .
\end{gathered}
$$

In eq(2), $r_{i}$ and $K_{i}$ stand respectively for the intrinsic growth rate and the carrying capacity of the species $i . s_{i, j}$ is the trophic effect ${ }^{5}$ of species $j$ on species $i$. The noise $\epsilon_{i}$ captures the environmental stochasticities affecting the growth of each species $i$ at each step $t$. It is assumed that the random variables $\epsilon_{i}(t)$ follow a Gaussian law, independent and identically distributed : $\epsilon \leadsto \mathcal{N}\left(0, \sigma^{2}\right)$. The parameter $e_{f}(t)$ in equation (3) represents the fishing effort of fleet $f$ (time spent at sea, in hour) and $q_{i, f}$ measures the catchability of species $i$ by fleet $f$. The number of the fleet $f$ (from $f=1$ to $f=4$ ) corresponds respectively to CC, CCA, $\mathrm{P}$ and T. The catch $H_{i, f}(t)$ of species $i$ by fleet $f$ at time $t$ is estimated using the Schaefer production function as in equation (3).

\subsection{Model and calibration inputs}

Values used to estimate the model parameters arise from different sources. Daily observations (catches and fishing efforts) from the landing points all along the coast are available from January 2006 to December 2010. Every month during this 60-month period, for each of the four fleets, fishing effort and catches were identified for the thirteen species, representing a total of 3360 observations. Moreover, we use Leopold (2004) and Fishbase ${ }^{6}$ to characterize the trophic interactions between

\footnotetext{
${ }^{5}$ positive if $j$ is a prey of $i$ and negative if $j$ is a predator of $i$.

${ }^{6}$ http: //www.fishbase.org
} 
species, including the sign of the relationship and the intrinsic growth rates. Initial stocks, catchabilities, trophic intensities values of the ecosystem as well as the standard deviation of growth were estimated through a least square method. This method consisted in minimizing the mean square error between the monthly observed catches $H_{i, f}^{\text {data }}$ and the catches $H_{i, f}$ simulated by the model as defined by eq(3):

$$
\min _{B_{0}, s, q, \sigma} \mathbb{E}_{\epsilon}\left[\sum_{t=\text { January }}^{\text {December } 2010} \sum_{i=1}^{13} \sum_{f}^{4}\left(H_{i, f}^{\text {data }}(t)-H_{i, f}(t)\right)^{2}\right] .
$$

Here $\left(B_{0}, s, q, \sigma\right)$ is the set of parameters to be identified. $B_{0}$ is the vector $(14 \times 1)$ of initial stock abundance (corresponding to december 2005 situation), $s$ is the matrix $(14 \times 14)$ of interactions between species including trophic intensities, $q$ is the matrix $(14 \times 4)$ of catchabilities and $\sigma$ is the standard deviation of random distribution $\epsilon$. Results of the calibration process are displayed in Table A.3 and Table A.4. For species that are not caught by a given fleet, catchability parameters $q_{i, f}$ were set at zero, as shown in Table A.3 (typically fleet 4).

The numerical implementations of the model are carried out with the scientific software SCILAB 5.3.3 ${ }^{7}$. The nonlinear optimization problem (Equation 4) was solved numerically using the Scilab routine 'optim_ga' which relies on an evolutionary (or genetic) algorithm ${ }^{8}$ as in Gourguet et al. (2013); Cissé et al. (2013); Hardy et al. (2013).

\subsection{Model outputs: ecological scores and risks}

The model is used to build and compare different fishing scenarios from $t_{1}=2011$ to the time horizon $T=2040$. In order to analyze and investigate sustainable futures for this fishery, we aim at evaluating the effort scenarios $e(t)$ in both ecological and economic terms. Thus indicators are computed to assess the performances and risks for both the ecosystem and the fishery. We first focus on biodiversity metrics. Although choice of biodiversity indicators remains debated -see e.g. Magurran (2007)- and every of them has limitations, we selected the species richness and marine trophic indicators.

\footnotetext{
${ }^{7}$ SCILAB (http://www.scilab.org) is an open-source software dedicated to scientific calculus and well suited to the simulation of dynamic systems.

${ }^{8}$ See http://help.scilab.org/docs/5.3.3/en_US/optim_ga.html for details on 'optim_ga'. A genetic algorithm is a search heuristic that mimics the process of natural evolution. This heuristic is routinely used to generate solutions to nonlinear optimization.
} 
Species richness. Species richness $\mathrm{SR}(t)$ indicates the estimated number of species represented in the ecosystem. In our model, it is assumed that a species disappears whenever its biomass falls under a predetermined viability limit $B_{\lim }$. This threshold $B_{\lim }$ which corresponds to a proxy of the ICES precautionary reference points is here set to $1 \%$ of the initial biomass $B_{0}$. The indicator SR is computed as follows:

$$
\mathrm{SR}(t)=\sum_{i} \mathbf{1}_{i}\left(B_{i}(t)\right)
$$

with the indicator (boolean) function

$$
\mathbf{1}_{i}(B)= \begin{cases}1 & \text { if } \quad B \geq B_{\lim , i} \\ 0 & \text { otherwise }\end{cases}
$$

Rare species have a relatively huge impact on this index.

Marine trophic index. The trophic level indicates the location of a species in a food web, starting with producers (e.g., phytoplankton, plants) at level 0, and moving towards primary consumers that eat primary producers (level 1) and secondary consumers that eat primary consumers (level 2 ), and so on. In marine ecosystems, the trophic levels vary from zero to five (top predators). The marine trophic index $\operatorname{MTI}(t)$ of an ecosystem is the sum of the trophic levels of the species present in this ecosystem, weighted by their relative abundances (Pauly and Watson, 2005). In our case the marine trophic index $\operatorname{MTI}(t)$ is therefore the weighted sum of the trophic levels of the thirteen species $T_{i}$ presented in Table 1, as follows:

$$
\operatorname{MTI}(t)=\frac{1}{N(t)} \sum_{i=1}^{13} T_{i} N_{i}(t) .
$$

Biodiversity risks. As mentioned in the introduction, the paper applies a stochastic viability approach consisting in the identification of control options that allow the dynamic system to remain in probability within a viable space defined by a combination of bio-economic constraints. The first biodiversity constraint is made up by the biodiversity indexes defined earlier, as no reference points exist for the studied species. This constraint is about maintaining both the SR index and the MTI above the minimum observed for the status quo scenario (defined in section 3.5 and denoted by SQS):

$$
\operatorname{SR}(t) \geq \min _{t=t_{1}, \ldots, T} \operatorname{SR}^{S Q S}(t), \quad \operatorname{MTI}(t) \geq \min _{t=t_{1}, \ldots, T} \operatorname{MTI}^{S Q S}(t)
$$


This constraint guarantees biodiversity sustainability and stands for a precautionary approach. Given a sequence of efforts $e(t)$, we denote by $\operatorname{PVP}(e)$ (Population Viability Probability) the probability that the biodiversity constraints are satisfied throughout time:

$$
\operatorname{PVP}(e)=\mathbb{P}(\text { Constraints (7) are satisfied. }),
$$

\subsection{Model outputs: economic scores and risks}

We now turn to the assessment of the fishing sector through the estimation of the production and profitability values and the bio-economic risks of the fishery. These are provided by eqs (9) and (12).

Food supply and food security. The total catches $H(t)$ within the fishery play the role of food supply:

$$
H(t)=\sum_{f} \sum_{i} H_{i, f}(t)
$$

The food security constraint is linked to the ability of the fishery to satisfy the local food consumption. This constraint is demanding because it reflects an increase in the local fish consumption at an annual rate of $d=3 \%$, following the demographic projection which predicts a doubling of the French Guiana's population by 2030 (INSEE, 2011). It is assumed however that fish species can be substituted, in the sense that a drop in the supply of one species can be compensated for, by a rise in the consumption of other species ${ }^{9}$. Consequently the food security reads

$$
H(t) \geq H(2010) \cdot(1+d)^{t}, \quad \text { for } t=t_{1}, \ldots, T
$$

where $d$ stands for the growth rate of the population and 2010 catches stand for the baseline. Given a sequence of efforts $e(t)$, we denote by $\operatorname{FVP}(e)$ (Food Viability probability) the probability

\footnotetext{
${ }^{9}$ Another modeling approach consists in introducing a utility function dealing with consumer preferences over a basket of species. For instance, Quaas and Requate (2013) assume that species are imperfect substitutes and consumers prefer diversity. Using a Dixit-Stiglitz CES utility function, demand functions for each species are derived from the representative household maximization program. It turns out that demand of each species is then a decreasing function of its own price and increasing with the prices of the other species. Such a work will be undertaken in the future for the French Guiana modeling. However it requires the calibration of a new set of parameters concerning the elasticity of substitution between the species.
} 
to comply with the food security constraint:

$$
\operatorname{FVP}(e)=\mathbb{P}(\text { Constraint }(10) \text { is satisfied. }) \text {, }
$$

Profits and profit viability. The profit $\pi_{f}(t)$ of each fleet $f$ is derived from the landings of each species $H_{i, f}$, the landing prices $p_{i, f}$, fixed $\operatorname{costs} c_{f}^{f}$, variable $\operatorname{costs} c_{f}^{v}$ and the crew share earnings $\beta_{f}$ as follows:

$$
\pi_{f}(t)=\left(1-\beta_{f}\right)\left(\sum_{i} p_{i, f} H_{i, f}(t)-c_{f}^{v} e_{f}(t)\right)-c_{f}^{f} .
$$

Table A.5 in Appendix A.3 provides the estimated values of the parameters involved. Prices, variable costs and fixed costs are those collected for year 2010. They are assumed to remain unchanged throughout the simulations. Share contract $\beta$ is the salary system commonly used in this fishery for fleets 2 and 4 . Crews are remunerated with a share of the landing value minus the variable costs. This share is usually 50\%. For fleets crews 1 and 3 are mostly made up of boat owners, occasionally assisted by a family member. If there is a pay system for these fleets, it differs from one owner to another. Hence, to simplify, we set $\beta_{f}=0$ for fleets 1 and 3 and $\beta_{f}=0.5$ for fleets 2 and 4 . Variable costs $c_{f}^{v}$ include fuel consumption, ice, food and lubricants. Equipment depreciation, maintenance and repairs are incorporated in the fixed $\operatorname{costs} c_{f}^{f}$.

To analyze the economic risks, we adopt a viability viewpoint and define the profit constraint for every fleet at any time:

$$
\pi_{f}(t) \geq 0, \quad \text { for } t=t_{1}, \ldots, T ., \text { for every } f=1, . ., 4
$$

This constraint holds for each fleet separately and not for the aggregated profit. Accounting for the uncertainties affecting the system dynamics, we define the 'Income Viability Probability' IVP $(e)$ of a given effort pattern $e(t)$ as the probability to comply with this profitability constraint ${ }^{10}$ :

$$
\operatorname{IVP}(e)=\mathbb{P}(\text { Constraint (13) is satisfied. }) .
$$

\footnotetext{
10 This assumption of non-negative profits in every month can be seen as restrictive and too demanding for some firms since profitable periods can compensate bad periods. However this constraint can be easily relaxed by regarding only the cumulative profits on the time period. Moreover this issue can also be addressed by considering crisis times as in Béné et al (2001), in which the constraint of profitability can be violated for a while.
} 


\subsection{Fishing scenarios}

To evaluate the viability of the French Guiana coastal fishery, we compare three different fishing scenarios at the time horizon $T=2040$. The status quo scenario (SQS) is exploratory without normative goals. Fishing efforts $e(t)$ are imposed throughout time and the ecosystem evolves accordingly. The two other scenarios, entitled economic scenario (ECOS) and eco-viability scenario (EVS) are 'normative' as they are forward-looking scenarios: one or several objectives are set at the beginning and the fishing effort strategies that allow to achieve the objectives are computed accordingly. From the calibrated model, the three scenarios were evaluated over thirty years and 100 replicates simulating the random variables and capturing the stochasticity $\epsilon()=.\left(\epsilon_{1}(),. \epsilon_{2}(),. \cdots, \epsilon_{T}().\right)$. These replicates stand for 10 cases of $\epsilon$ in period 1 and 10 cases in period 2 .

The status quo scenario (SQS). This scenario simulates a steady fishing effort based on the mean pattern of the observed efforts between 2006 and 2010:

$$
e_{f}(t)=\bar{e}_{f}, \quad \text { for } f=1, \ldots, 4 \quad \text { for } t=t_{1}, \ldots, T
$$

with $\bar{e}_{f}$ representing the mean effort monthly observed between 2006 and 2010 for the fleet $f$.

The economic scenario (ECOS). This scenario maximizes the net present value of all the future profits aggregated among all fleets $\pi(t)$ :

$$
\pi(t)=\sum_{f} \pi_{f}(t)
$$

The net present value depends on fishing effort patterns as follows:

$$
\operatorname{NPV}(e)=\mathbb{E}_{\epsilon}\left[\left(\sum_{t=t_{1}}^{T-1}(1+\gamma)^{t_{1}-t} \pi(t)\right)+\gamma^{-1} \cdot(1+\gamma)^{1-T} \pi(T)\right],
$$

where $\mathbb{E}$ is the mathematical expectation and $\gamma$ stands for the discount rate set at $\gamma=3 \%$. We assume that profits continue indefinitely at the level corresponding to the one during the terminal year, $\pi(T)$. Given a control $e(t)$, the expectation is approximated by the mean of 100 profits derived by the 100 replicates. The optimal program underlying the ECO scenario is defined by:

$$
\max _{e\left(t_{1}\right), e\left(t_{2}\right)} \operatorname{NPV}(e)
$$

where feedback controls $e\left(t_{1}\right)$ and $e\left(t_{2}\right)$ mean respectively $e\left(t_{1}, B\left(t_{1}\right)\right)$ and $e\left(t_{2}, B\left(t_{2}\right)\right)$. 
Note that this optimal strategy does not guarantee individual profitability among all fleets but represents the viewpoint of a central planner maximizing the expected sum of discounted profits at the aggregated scale.

Regarding the choice of effort and control rules, it is assumed that the fishing efforts rely on a feedback control strategy $e_{f}(t, B)$ that can be adapted every 15 years in such a way that fishing effort choices are made at the start of the two simulation periods ${ }^{11}$. The feedback strategy relies on a 'non-anticipative' stochastic control approach (Shapiro et al., 2009). At the first period $t_{1}$ of the decision process, the fishing effort is assumed to depend only on the information on the initial state $B\left(t_{1}\right)$ available throughout the period. Thereby at the start of the second period $t_{2}$, we have a number of possible states of the biomass induced by the different replicates of $\epsilon$ drawn randomly. For each of these possible states $B\left(t_{2}\right)$, a new decision about fishing effort is taken $e\left(t_{2}, B\left(t_{2}\right)\right)$ again in the form of a feedback control depending on the state of the eco-system at time $t_{2}$ :

$$
e_{f}(t)= \begin{cases}e_{f}\left(t_{1}, B\left(t_{1}\right)\right) & \text { for } t=t_{1}, \ldots, t_{1}+179 \\ e_{f}\left(t_{2}, B\left(t_{2}\right)\right) & \text { for } t=t_{2}, \ldots, T\end{cases}
$$

where $t_{1}=1$ and $t_{2}=180$ are decisive months. Moreover, it is assumed that maximum feasible efforts per month is 500 hours per vessel. Details of the numerical computations for the optimization in this stochastic context are displayed in Appendix A.1.

The Eco-viability scenario (EVS). The purpose of this scenario is to provide a satisfactory balance over time between fleet profitability, biodiversity viability and food security. This strategy is assessed in terms of probability for these three objectives to be met over time. Thus the ecoviability probability can be written as:

$$
\operatorname{EVP}(e)=\mathbb{P}(\text { Constraints, }(7),(10) \text { and }(13) \text { are satisfied })
$$

The viable efforts for EVS are obtained by maximizing the eco-viability probability:

$$
\max _{e\left(t_{1}\right), e\left(t_{2}\right)} \operatorname{EVP}(e)
$$

\footnotetext{
${ }^{11}$ A refined time decomposition for fishing intensities (for instance, a five-year time step) would have improved the analysis by capturing a broader intertemporal flexibility in fishing strategy. However, it would have required very demanding computation times given the dimension of the system considered.
} 
The computation of feedback efforts $e\left(t_{1}\right)$ and $e\left(t_{2}\right)$ is similar to the ECOS scenario, in the sense that non anticipative strategies are applied for periods $t_{1}$ and $t_{2}$. The probability $\mathbb{P}()$ is approximated by the proportion of viable occurrences namely the number of viable replicates divided by 100 .

\section{Results}

Appendix A.2 provides details on the quality of the calibration and Appendix A.3 reports the estimated parameters. Figure 2 displays the set of optimal effort $e_{f}(t, B)$ solutions of the intertemporal programs corresponding to each normative scenario $\left(u^{\text {EVS }}\right.$ and $\left.u^{\text {ECOS }}\right)$ for the two parts of the simulation. The box plots shown in the second part exhibit the range of effort multipliers achieving the scenarios depending to uncertainties on growth and stochasticity. These effort multipliers are computed from the fishing levels ${ }^{12}$ normalized by the status quo level. Table (2) presents the economic and ecological viability probabilities and the net present values for each scenario.

\subsection{Status quo scenario: Weak economically and unviable for food security}

This scenario corresponds to a case where fishing efforts are maintained constant during the 30 years of the simulation at levels equivalent to those observed between 2006 and 2010. The corresponding effort multipliers are therefore equal to 1.

The numerical simulations of figure 3 -c first show that from 2030, the maximum total catches pass below the food security threshold. Thus SQS fails to satisfy the food security requirement for all simulations $\left(\operatorname{FVP}\left(u^{S Q S}\right)=0\right)$. Economically as well, SQS does not do great: 40 out of the 100 simulations lead to conditions where the profitability constraints are satisfied $\left(\operatorname{IVP}\left(u^{S Q S}\right)=0.4\right)$. This scenario yields a net present value equals to 42.8 millions of euros cumulated over the 30 years (Table 2).

Figures 3 -a and b show that the species richness falls to the 10 viability threshold, and few species (sharks, Gillbacker catfish and Goliath Grouper) disappear. The marine trophic index MTI

\footnotetext{
${ }^{12}$ We assume that the number of vessels remains the same during the simulation time (65 for $f=1,60$ for $f=2,46$ for $f=3$ and 9 for $f=4$ ). The French Guiana coastal fishery is regulated and the number of active vessels remained relatively stable in recent years. By keeping constant the number of vessels, we have not modeled vessel entry and exit. Recent papers dealing with such a viability approach (Gourguet et al. (2013); Doyen et al. (2012) and Péreau et al. (2012)) used vessel-based monitoring.
} 
shows a very slow decline but remains above the viability threshold ${ }^{13}$

\subsection{Economic scenario (ECOS): Ecologically, economically and food security unviable}

The economic scenario seeks to ensure the maximization of the present (discounted) total profit at the aggregated fleet level. It is characterized by the highest effort multiplier, particularly for fleets 1 and 3 (Figure 2-b) for which the specific multipliers reach their maximum values, while the activity of the two other fleets (2 and 4) is significantly reduced especially during the first period. As a consequence, the profitability constraint is not satisfied for these last two fleets - as shown in Figures 4-e and g. Through ECOS, the fishery yields the highest net present value, around 196.2 millions of euros. However this positive economic outcome is achieved at the detriment of the ecological viability of the system $\left(\operatorname{PVP}\left(u^{E C O S}\right)=0\right)$. In particular the species richness falls to 8 (cf. Figure 4 -a). In addition to the 4 species that were already getting extinct under SQS, two additional species are projected to disappear under ECOS: fat snook and bressou catfish. Finally the high harvesting levels induced by this scenario allow to satisfy the food security constraints in 48 out of $100 \operatorname{runs}\left(\operatorname{FVP}\left(u^{E C O S}\right)=0.48\right)$.

\subsection{Eco-viability scenario (EVS): a viable strategy from economic, ecological and food security viewpoints}

The eco-viability scenario aims at satisfying simultaneously IVP, PVP and FVP constraints. The numerical simulations show that the effort multipliers associated with the 'eco-viable' trajectories are higher than the SQS baseline (Figure 2-a). These effort multipliers are consistent as the corresponding fleets are typically small-scale with relatively low fishing efforts (less than 15 hours per week). From an ecological perspective, the simulations indicate that the PVP objective is satisfied $100 \%$ of the time $\left(\operatorname{PVP}\left(u^{E V S}\right)=1\right)$ although - as it was the case for the SQ scenario - the SR index falls to the biodiversity threshold around the year 2025 (Figures 5-a and b). The profitability constraints are respected for all trajectories $\left(\operatorname{IVP}\left(u^{E V S}\right)=1\right)$ and the food security condition is satisfied for $90 \%$ of the trajectories tested: only 10 of these do not satisfy the food security constraint $\left(\operatorname{FVP}\left(u^{E V S}\right)=0.9\right)$. This happens essentially during the last years of the simulations ((Figure 5-c) when the population has doubled and the demand for food is higher than

\footnotetext{
13 As most of the species accounting for the modeled ecosystem have high trophic level, the MTI index is not sensitive to changes in the species abundances.
} 
ever. This scenario yields a net present value ranging between 109.4 and 110.9 millions according to the set of possible fishing efforts.

\section{Discussion}

\subsection{Eco-viability as a way to integrate ecological, economics but also social considerations}

As expected, the economic scenario (ECOS) yields the greatest net present value over the simulation period (Figure 7) but it is a no-win strategy because it is ecologically and economically risky (Figure 6). As in Cissé et al. (2013) and Doyen et al. (2012), this scenario put emphasis on the most efficient fleets in economic terms. Here the fleets 1 and 3 exhibit the best economic performances even if their catches are lower in terms of volumes. In fact these vessels have the lowest fixed costs due to the scanty equipment involved and benefit from the high selling prices since their products are directly sold to the consumers (i.e. no middlemen).

The eco-viability scenario (EVS) appears as the most conservative management strategy and the stochastic approach guarantees its sustainability in an uncertain context. This scenario exhibits a high probability to achieve the economic, ecological and food security constraints together. Moreover this scenario reveals an increase of the net present value between 66.1 and $68.1 \mathrm{M} €$ compared to baseline SQS. Contrasted with ECOS, the economic cost of sustainability can be evaluated by the difference of cumulative profits between these two scenarios (EVS and ECOS). This cost between 85.3 and $86.8 \mathrm{M} €$ (196.2 minus 109.4-110.9) has to be balanced with the benefit of a high probability to ensure a viable management of the fishery (Figure 7). The ecological sustainability gained through the EVS has to be compared with the unsustainability of ECOS both in terms of species richness and in probability of remaining above the thresholds, and in terms of probability with the SQ scenario (Figure 8). Finally the benefits of EVS also go beyond the satisfaction of the food security constraints (at least until 2035) as it helps maintaining positive profits for all the fleets in the fishery.

Identifying the conditions that ensure the economic and environmental sustainability and food security is an important advantage of EVS. Moreover, as demonstrated in Doyen and Martinet (2012), viability is closely related to the maximin (Rawlsian) approach with respect to intergen-

erational equity. It thus contributes to sustain ecosystem and services over the long run. As 
recognized by Baumgartner and Quaas (2009), viability approach appears as a condition for strong sustainability purposes since several criteria are taken into account and reached separately.

While Péreau et al. (2012) consider the maintenance of the fleets within the fishery as a social constraint, this paper includes for the first time in a bio-economic model food security issues as a new social constraint. This issue is important especially for small-scale fisheries Hardy et al. (2013). As pointed out by Béné (2006); Béné et al. (2010), it is also important to include population growth in the management plans of small-scale fisheries because, in many developing countries, fishes are the main protein provider.

\subsection{Eco-viability and EBFM}

The viability approach appears as a well-suited modeling framework for EBFM to deal with complexity, uncertainties and precautionary approaches. Indeed, the viability approach, simultaneously accounts for dynamic complexities, risks and uncertainty, sustainability objectives for fisheries. In particular, Cury et al. (2005) and Doyen et al. (2007) show how the method can potentially be useful for integrating ecosystem considerations for fisheries management. Mullon et al. (2004) and Chapel et al. (2008) emphasize the ability to address complex dynamics in this framework. The computational and mathematical modeling methods proposed in this paper through EVS are motivated by a similar prospect.

One major advantage of the eco-viability approach is the fact that the viability framework

is dynamic and thus makes it possible to capture the interactions and co-evolution of marine biodiversity and fishing. The dynamics can potentially include complex mechanisms such as trophic interactions, competition, metapopulation dynamics or economic investment processes. Here the focus is both on trophic and technical interactions through a multi-fleet and multi-species context. This paper contributes to the guidance on how to operationalize EBFM especially in tropical smallscale fishery, where data and reference points are often missing. In addition, taking into account the food security objective to deal with the potential rise of fish demand through local population growth is a step forward for an ecosystem approach (Hilborn, 2011).

The need of robust and precautionary approach is relevant to tackle EBFM particularly when knowledge is insufficient (Pikitch et al., 2004). The stochastic viability approach used in this work appears as a well suited way to operationalize sustainable small-scale fishery in an uncertain context. 
As in Doyen et al. (2012) and Gourguet et al. (2013), stochastic scenarios presented here allow accounting for the complexities and uncertainties of mechanisms at play, particularly their nonlinearity. Ecological dynamics and technical interactions but also trophic webs, or environmental (habitat, climatic) uncertainties are addressed. In this paper inasmuch no reference points are available for species studied, we adopt a precautionary approach considering both two ecological indexes with reasonable chosen thresholds. The computed set of fishing efforts of normative scenarios by the non-anticipativity stochastic method, give high improvements compared to Cissé et al. (2013) because they rely on feedback controls and consequently more adaptive accounting for uncertainties affecting the exploited ecosystem. The EVS scenario exhibits a sustainable match with economic and ecological issues together with food security constraint with a high probability.

\subsection{Decision support for the French Guiana small-scale fishery}

The first assessment of the French Guiana small-scale coastal fishery has been carried out by Cissé et al. (2014) stressing the socio-economic importance of this fishery. In fact due to its status of European overseas territory, regulation tools are derived from commonly used national and European fisheries management systems. The technical management measures consist of maximum net length $(2500 \mathrm{~m})$, minimum mesh size $(40 \mathrm{~mm})$, marine protected area $\left(8 \mathrm{~km}^{2}\right)$ and trawl ban under $30 \mathrm{~m}$ deep. The access to the fishery is regulated by European and regional licenses. There is no quota for catches and no limitations concerning exploited species and their size. The only aim of the current management strategy is to prevent fishing activity by unauthorized boats. Actually, up to now, as many tropical multi-species fisheries, there are no studies on the stock status for the main exploited species. The data monitoring system, implemented since 2006, does not present time series data enough longer to tackle such goals. Nevertheless the available data are satisfactory to bioeconomic modeling purpose as in Cissé et al. (2013).

The present study provides new insights in complement to Cissé et al. (2013), improving our understanding of the case study. First, fishing scenario outputs show that fishing performance, including food supply and fleet profitability, can be increased or sustained with lesser impact to marine ecosystem. Particularly EVS aims to reconcile economic and ecological sustainability with the growing food demand contributing hence to food security, with a high probability. Secondly, it appears that the loss of species cannot be avoided. This loss of biodiversity could potentially alter 
some ecosystem services (not taken into account in this model) and the outcomes of the fishery itself in the long run. Depending on the endangered stocks, conservation measures for the productive and reproductive capacities of these stocks should be taken. Banning fishing in nursery zones or promoting more selective fishing techniques could be an alternative. Lastly, EVS does not entail a severe reduction of harvesting, the fishing effort remains relatively high compared to SQS.

Contrasted with SQS, EVS gives insights on the status of the French Guiana coastal fishery. The fishery is not currently fully exploited and may support higher fishing level without jeopardizing ecological and economic sustainability. In fact, this fishery seems not to suffer from overcapacity. However, we are aware that the results and the scenarios have to be considered with cautious. Nevertheless, we can first argue that the reliability of the analysis derive from the stochastic nature of both the model and the assessments. Furthermore Cissé et al. (2013) analyzed the sensitivity of the same model with respect to estimated parameters, showing that the estimated parameters are meaningful and acceptable for modeling purposes. In the way to improve the robustness of the model, our knowledge of the complex ecosystem and thus the management plans, the methodological interest of sustaining the Fishery Information System of the French Guiana coastal fishery appears obvious.

\subsection{Perspectives}

By reconciling food security, biodiversity conservation and economic sustainability, this paper is an example for operationalizing EBFM and is a step forward in the understanding, the assessment and the management of the French Guiana coastal fishery. Therefore many improvements are needed concerning the calibration method, the economic and ecological sides of the model. First of all, the uncertainty underling the model has been estimated within the calibration process of the unknown biological parameters of the model, by least square method. A more accurate option is to calibrate the noise parameter ex post with for instance a Kalman filter for nonlinear process (see Kwasniok (2012)).

Moreover on the economic side, the assumption of keeping fixed some economic parameters during the period simulation has to be relaxed. Taking into account stochasticity on costs as fuel price is necessary to improve the predictions of the model. The assumption of fixed prices has to be relaxed by modeling the demand side as in Datta and Mirman (1999) and introducing 
consumer preferences for variety species as in Quaas and Requate (2013). Another step will consist on considering the illegal fishing activity of foreign fleets (from Guiana, Suriname and Brazil), which are not yet taken into account in the study.

Furthermore on the ecological side, it will be fruitful to compare the present results with other simplified dynamic models, as Gompertz model for instance (see Mutshinda et al. (2009)). In fact there is no proof that the Lotka-Volterra dynamics used in this work is the more accurate for the French Guyana coastal ecosystem. Symbiotic relation or negative interactions have to be considered. It would also be interesting to extend the number of species in order to include the effects of fishing activities on the dynamics of other species (such as mammals, turtles or birds) and on plankton dynamics as suggested by Pikitch et al. (2004). Lastly, another interesting goal would be to include the effects of climate changes, for instance sea surface temperatures (Keyl and Wolff, 2008; Thébaud and Blanchard, 2011).

\section{Acknowledgments}

This work was completed with the financial support of the ANR (French National Research Agency) as part of the ADHOC program, the ERDF (European Regional Development Fund) under the DEPECHE program and IFREMER. We thank all the fishermen who agreed to provide economic data as well as all the observers who collected the other fishery data sets each day.

\section{Bibliography}

Baumgartner, S. and M. F. Quaas (2009), 'Ecological-economic viability as a criterion of strong sustainability under uncertainty', Ecological Economics 68: 2008 - 2020.

Béné (2006), 'Small-scale fisheries: assessing their contribution to rural livelihoods in developing countries.' FAO Fisheries Circular 1008, FAO, Rome.

Béné, C., L. Doyen, and D. Gabay (2001), 'A viability analysis for a bio-economic model', Ecological Economics 36: 385-396.

Béné, C., B. Hersoug, and E. H. Allison (2010), 'Not by Rent Alone: Analysing the Pro-Poor Functions of Small-Scale Fisheries in Developing Countries', Development Policy Review 28: $325-358$. 
Butchart, S. H. M. and M. e. Walpole (2010), 'Global Biodiversity: Indicators of Recent Declines', Science 328: 1164-1168.

Chapel, L., G. Deffuant, S. Martin, and C. Mullon (2008), 'Defining yield policies in a viability approach', Ecological Modelling 212: 10-15.

Cissé, A., S. Gourguet, L. Doyen, F. Blanchard, and J.-C. Péreau (2013), 'A bio-economic model for the ecosystem-based management of the coastal fishery in French Guiana', Environment and Development Economics 18: 245-269.

Cissé, A. A., F. Blanchard, and O. Guyader (2014), 'Sustainability of tropical small-scale fisheries: Integrated assessment in French Guiana', Marine Policy 44: 397 - 405.

Cury, P. A. and V. Christensen (2005), 'Quantitative ecosystem indicators for fisheries management - Introduction', Ices Journal of Marine Science 62: 307-310.

Cury, P. M., C. Mullon, S. M. Garcia, and L. J. Shannon (2005), 'Viability theory for an ecosystem approach to fisheries', Ices Journal of Marine Science 62: 577-584.

Datta, M. and L. J. Mirman (1999), 'Externalities, Market Power, and Resource Extraction', Journal of Environmental Economics and Management 37: 233 - 255.

De Lara, M., E. Ocana, R. Oliveros-Ramos, and J. Tam (2012), 'Ecosystem Viable Yields', Environmental Modeling \& Assessment 17: 565-575.

Doyen, L., A. Cissé, S. Gourguet, L. Mouysset, P.-Y. Hardy, C. Béné, F. Blanchard, F. Jiguet, J.-C. Péreau, and O. Thébaud (2013), 'Ecological-economic modelling for the sustainable management of biodiversity', Computational Management Science 10: 353-364.

Doyen, L., M. De Lara, J. Ferraris, and D. Pelletier (2007), 'Sustainability of exploited marine ecosystems through protected areas: A viability model and a coral reef case study', Ecological Modelling 208: 353-366.

Doyen, L. and V. Martinet (2012), 'Maximin, viability and sustainability', Journal of Economic Dynamics and Control 36: $1414-1430$. 
Doyen, L., O. Thébaud, C. Béné, V. Martinet, S. Gourguet, M. Bertignac, S. Fifas, and F. Blanchard (2012), 'A stochastic viability approach to ecosystem-based fisheries management', Ecological Economics 75: $32-42$.

FAO (2012), The state of world fisheries and aquaculture, State of World Fisheries and Aquaculture (FAO), Rome.

Gabrel, V., C. Murat, and A. Thiele (2014), 'Recent advances in robust optimization: An overview', European Journal of Operational Research 235: 471 - 483.

Garcia, S., E. H. Allison, N. Andrew, C. Béné, G. Bianchi, G. De Graaf, D. Kalikoski, R. Mahon, and L. Orensanz (2008), Towards integrated assessment and advice in small-scale fisheries : principles and processes, FAO fisheries and aquaculture technical paper;515, Rome: FAO.

Garcia, S., C. Zerbi, A.and Aliaume, T. Do Chi, and G. Lasserre (2003), The ecosystem approach to fisheries. Issues, terminology, principles, institutional foundations, implementation and outlook, FAO, Fishery Resources Div., Rome (Italy).

Godfray, H., J. Beddington, I. Crute, L. Haddad, D. Lawrence, J. Muir, J. Pretty, S. Robinson, S. Thomas, and C. Toulmin (2010), 'Food security: the challenge of feeding 9 billion people', Science 327: 812-8.

Gourguet, S., C. Macher, L. Doyen, O. Thébaud, M. Bertignac, and O. Guyader (2013), 'Managing mixed fisheries for bio-economic viability', Fisheries Research 140: 46 - 62 .

Grafton, R. Q., T. Kompas, and R. W. Hilborn (2007), 'Economics of overexploitation revisited', Science 318: 1601-1601.

Hall, S. J. and B. Mainprize (2004), 'Towards ecosystem-based fisheries management', Fish and Fisheries 5: 1-20.

Hardy, P.-Y., C. Béné, L. Doyen, and A.-M. Schwarz (2013), 'Food security versus environment conservation: A case study of Solomon Islands' small-scale fisheries', Environmental Development 8: $38-56$.

Hilborn, R. (2011), 'Future directions in ecosystem based fisheries management: A personal perspective', Fisheries Research 108: 235 - 239. 
INSEE (2011), 'Projections de population åi ¿ $\frac{1}{2}$ l'horizon 2040, Plus d'un demi-million de Guyanais', Technical report, INSEE.

Jennings, S. (2005), 'Indicators to support an ecosystem approach to fisheries', Fish and Fisheries 6: $212-232$.

Keyl, F. and M. Wolff (2008), 'Environmental variability and fisheries: what can models do?' Reviews in Fish Biology and Fisheries 18: 273-299.

King, J. R. and G. A. Mcfarlane (2006), 'A framework for incorporating climate regime shifts into the management of marine resources', Fisheries Management and Ecology 13: 93-102.

Kwasniok, F. (2012), 'Estimation of noise parameters in dynamical system identification with Kalman filters', Physical Review E 86.

Leopold, M. (2004), Guide des poissons de mer de Guyane, Ifremer.

Magurran, A. E. (2007), 'Species abundance distributions over time', Ecology Letters 10: 347-354.

Marasco, R. J., D. Goodman, C. B. Grimes, P. W. Lawson, A. E. Punt, and T. J. Quinn (2007), 'Ecosystem-based fisheries management: some practical suggestions', Canadian Journal of Fisheries and Aquatic Sciences 64: 928-939.

Millennium Ecosystem Assessment (2005), Ecosystems and Human Well-Being: Current State and Trends. Findings of the Condition and Trends Working Group. Millennium Ecosystem Assessment Series, Island press, Washington DC.

Mullon, C., P. Cury, and L. Shannon (2004), 'Viability model of trophic interactions in marine ecosystems', Natural Resource Modeling 17: 71-102.

Mutshinda, C. M., R. B. O'Hara, and I. P. Woiwod (2009), 'What drives community dynamics?' Proceedings of the Royal Society B: Biological Sciences 276: 2923-2929.

Myers, R. A. and B. Worm (2003), 'Rapid worldwide depletion of predatory fish communities', Nature 423: 280 - 283 . 
Pauly, D. and R. Watson (2005), 'Background and interpretation of the 'Marine Trophic Index' as a measure of biodiversity', Philosophical Transactions of the Royal Society B-Biological Sciences 360: $415-423$.

Péreau, J.-C., L. Doyen, L. Little, and O. Thébaud (2012), 'The triple bottom line: Meeting ecological, economic and social goals with individual transferable quotas', Journal of Environmental Economics and Management 63: 419 - 434.

Pikitch, E. K., C. Santora, E. A. Babcock, A. Bakun, R. Bonfil, D. O. Conover, P. Dayton, P. Doukakis, D. Fluharty, B. Heneman, E. D. Houde, J. Link, P. A. Livingston, M. Mangel, M. K. McAllister, J. Pope, and K. J. Sainsbury (2004), 'Ecosystem-Based Fishery Management', Science 305: 346-347.

Plaganyi, E. (2007), Models for an ecosystem approach to fisheries, Fisheries Technical Paper (FAO) No. 477.

Quaas, M. and T. Requate (2013), 'Sushi or fish fingers? Seafood diversity, collapsing fish stocks, and multi-species fishery management', The Scandinavian Journal of Economics 115(2): 381422.

Rice, J. C. (2000), 'Evaluating fishery impacts using metrics of community structure', Ices Journal of Marine Science 57: 682-688.

Rice, J. C. and S. M. Garcia (2011), 'Fisheries, food security, climate change, and biodiversity: characteristics of the sector and perspectives on emerging issues', ICES Journal of Marine Science: Journal du Conseil .

Sanchirico, J. N., M. D. Smith, and D. W. Lipton (2008), 'An empirical approach to ecosystembased fishery management', Ecological Economics 64: 586-596.

Shapiro, A., D. Dentcheva, and A. Ruszczynski (2009), Lectures on Stochastic Programming, Society for Industrial and Applied Mathematics.

Thébaud, O. and F. Blanchard (2011), Fishing the Food Web: integrated analysis of changes and drivers of change in fisheries of the Bay of Biscay, Wiley-Blackwell, pp. 90-104. 
Thébaud, O., L. Doyen, J. Innes, M. Lample, C. Macher, S. Mahévas, C. Mullon, B. Planque, M. Quaas, T. Smith, and Y. Vermard (2014), 'Building ecological-economic models and scenarios of marine resource systems: Workshop report', Marine Policy 43: 382 - 386.

Ye, Y., K. Cochrane, G. Bianchi, R. Willmann, J. Majkowski, M. Tandstad, and F. Carocci (2012), 'Rebuilding global fisheries: the World Summit Goal, costs and benefits', Fish and Fisheries 14: $174-185$. 
Table 1: The thirteen selected species representing about $90 \%$ of the catches of the fishery.

\begin{tabular}{|l|l|c|}
\hline Common name & Scientific name & Trophic level $T_{i}$ \\
Acoupa weakfish & Cynoscion acoupa & 4.05 \\
Crucifix sea catfish & Hexanematichtys proops & 4.35 \\
Green weakfish & Cynoscion virescens & 4.03 \\
Common snooks & Centropomus parallelus, Centropomus undecimalus & 4.2 \\
Sharks & Sphyrna lewini, Carcharhinus limbatus, Mustelus higmani & 4.5 \\
Smalltooth weakfish & Cynoscion steindachneri & 3.25 \\
South american silver croaker & Plagioscion squamosissimus & 4.35 \\
Tripletail & Lobotes surinamensis & 4.04 \\
Gillbacker sea catfish & Arius parkeri & 4.11 \\
Bressou sea catfish & Aspistor quadriscutis & 3.5 \\
Goliath grouper & Epinephelus itajara & 4.09 \\
Flathead grey mullet & Mugil cephalus & 2.13 \\
Parassi mullet & Mugil incilis & 2.01 \\
\hline
\end{tabular}


Table 2: The viability probabilities and net present values of the different fishing scenarios

\begin{tabular}{|c|c|c|c|c|c|}
\hline${ }_{\text {Scenarios }}$ Probabilities & PVP & FVP & IVP & EVP & NPV(M euros $)$ \\
\hline Status quo & 1 & 0 & 0.4 & 0 & 42.8 \\
\hline Economic & 0 & 0.48 & 0 & 0 & 196.2 \\
\hline Eco-viability & 1 & 0.9 & 1 & 0.9 & $109.4-110.9$ \\
\hline
\end{tabular}




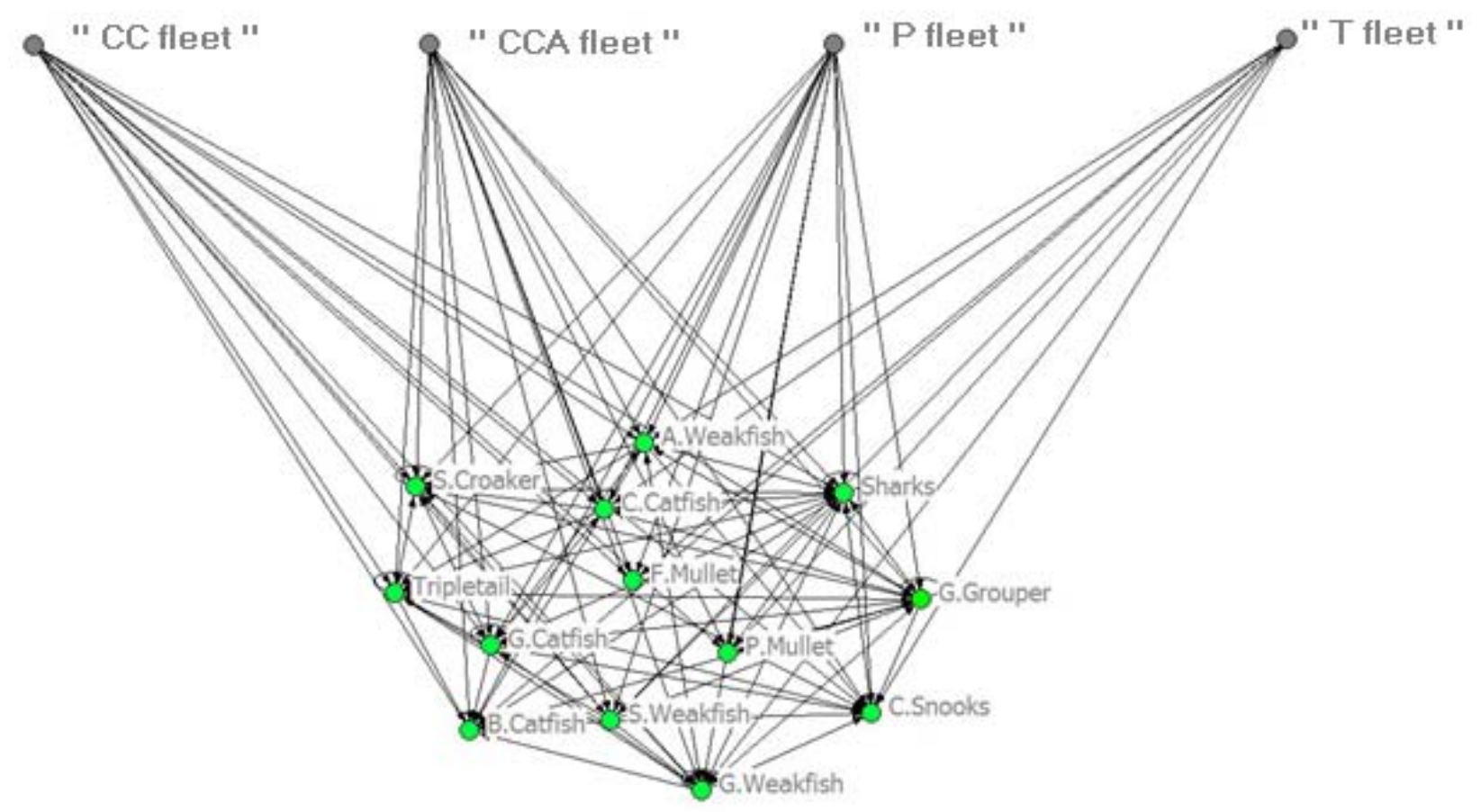

Figure 1: Food web of the thirteen main species and the four fleets exploiting them in the French Guiana coastal fishery. 
(a) Economic Scenario

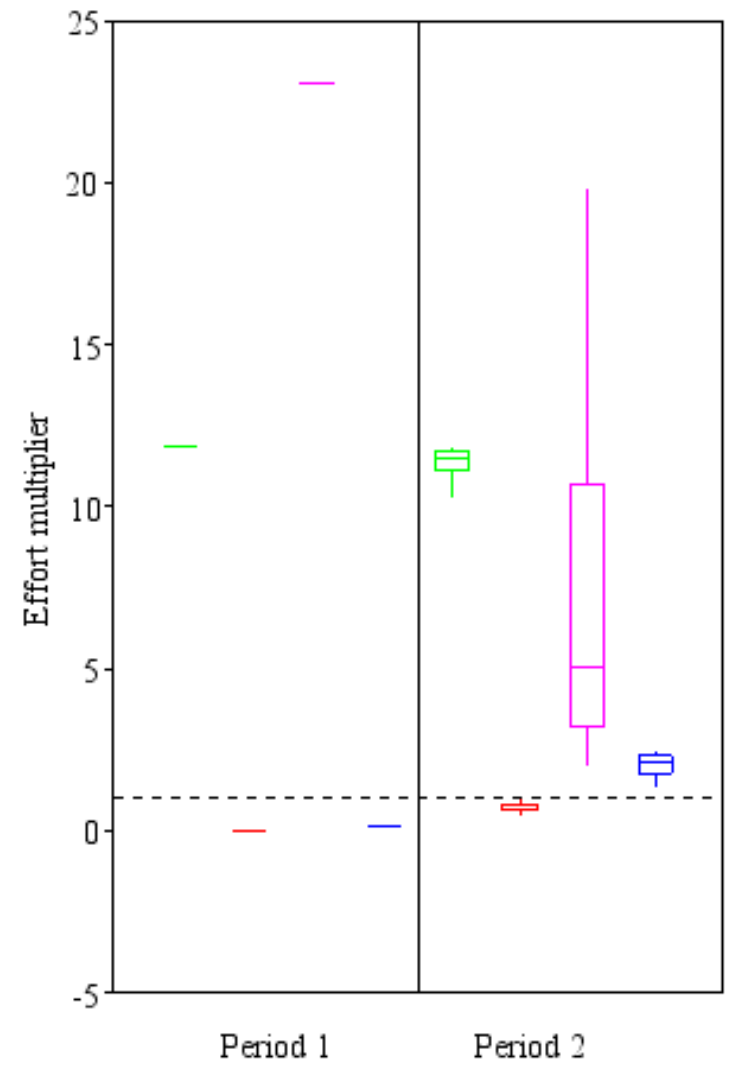

(b) Eco-viability Scenario

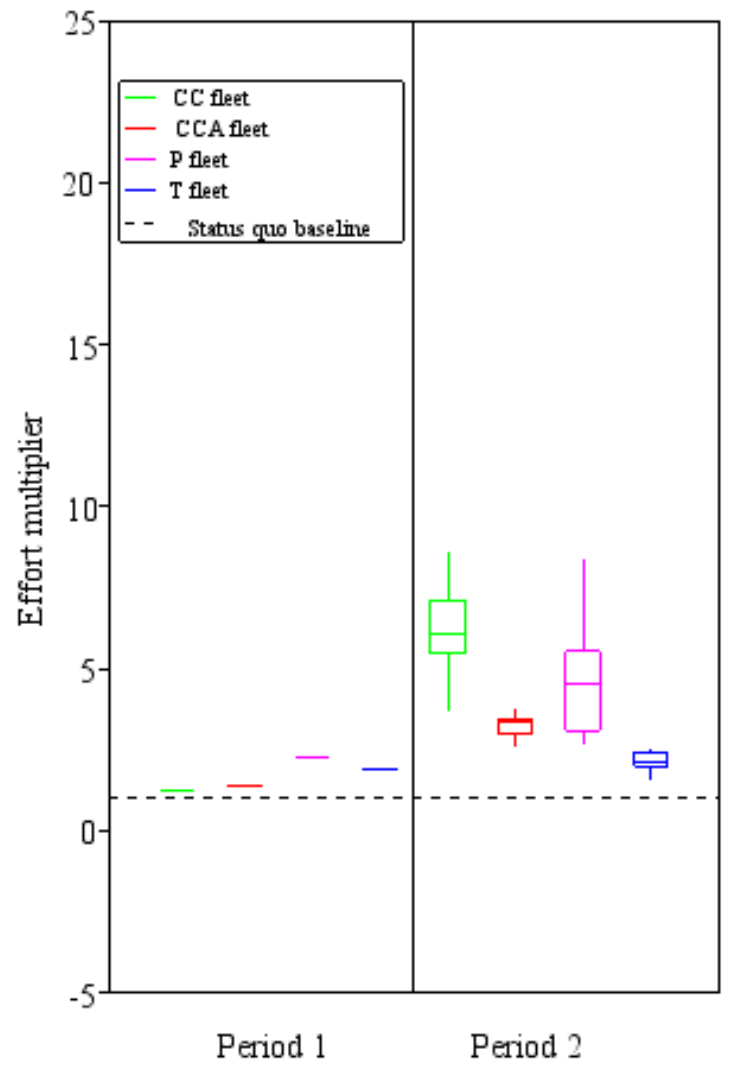

Figure 2: Fishing effort multipliers, by scenario and fleet (from 1 to 4), based on the comparison between effort $e_{f}(t)$ and the mean pattern of efforts $\bar{e}_{f}$ between 2006 and 2010: $u_{f}(t)=\frac{e_{f}(t)}{\bar{e}_{f}}$. The box plots in the second simulation period show the different prospective fishing efforts according to uncertainties. 
(a)
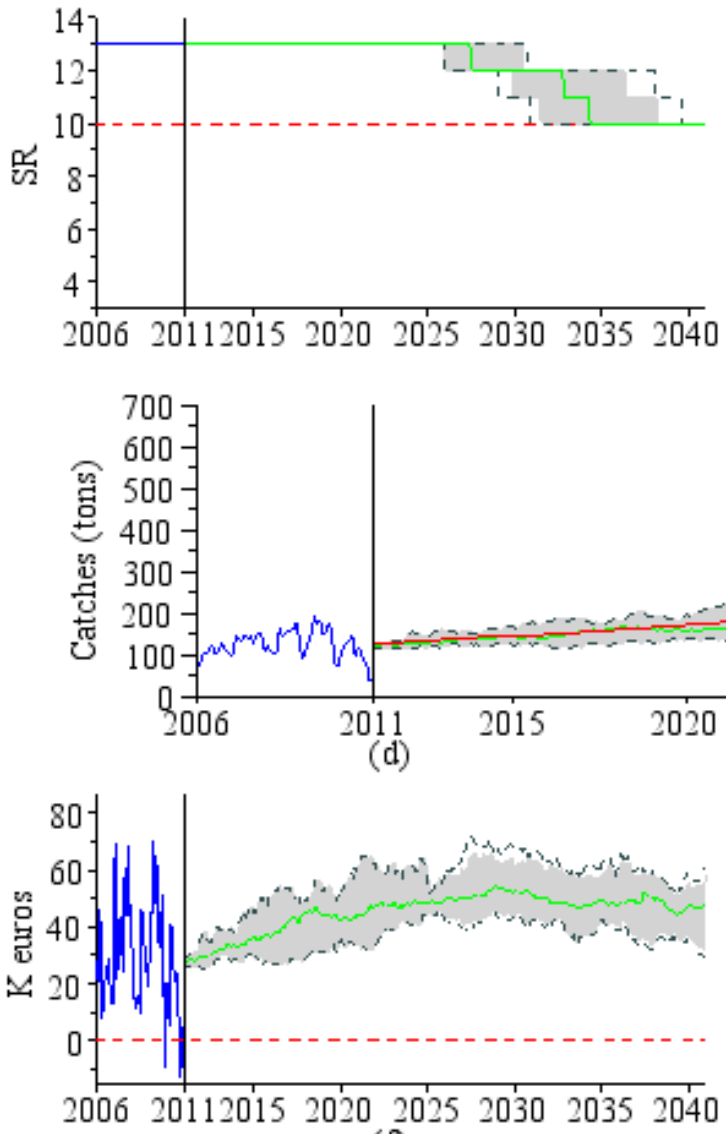

(f)

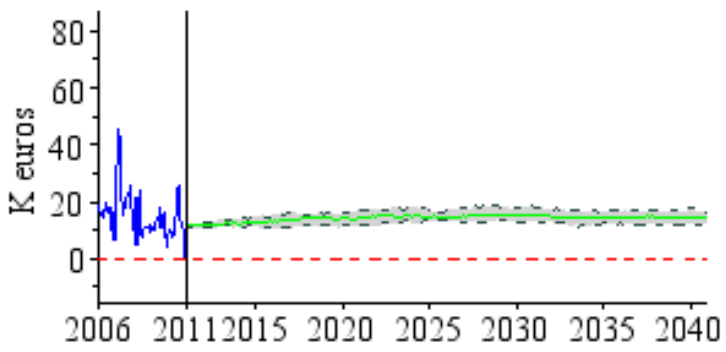

(b)

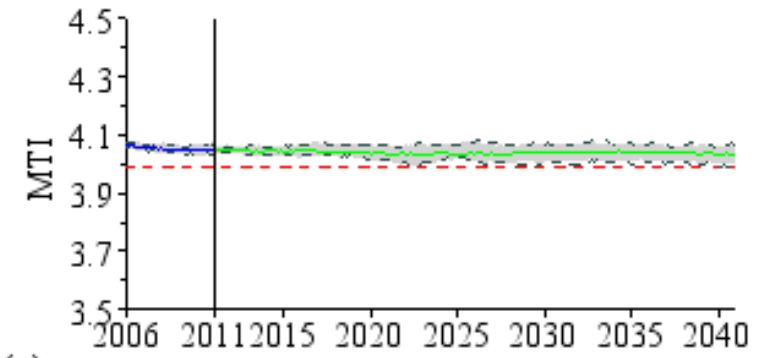

(c)

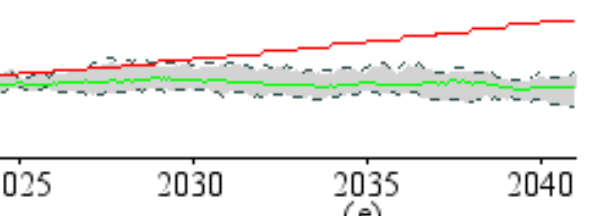

(e)

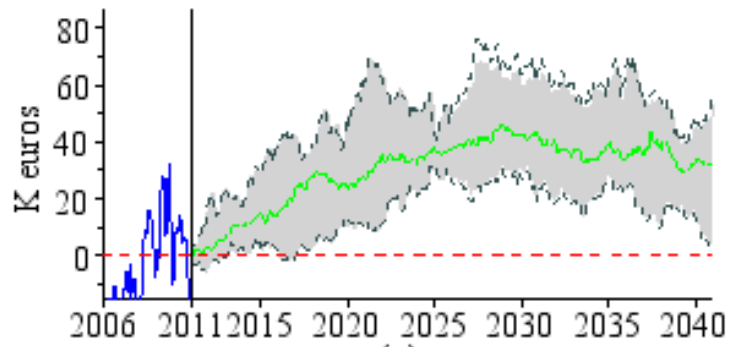

(g)

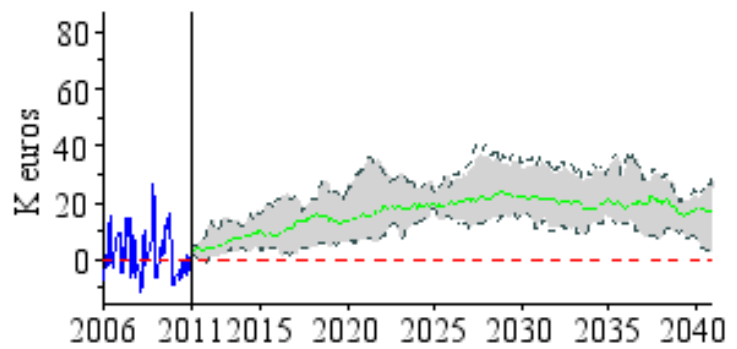

Figure 3: Main outputs for the status quo scenario (SQS) with $u_{f}^{S Q S}(t)=1$ : Evolution of the species richness (a), marine trophic index (b), total catches (c) and profits by fleet (d. fleet 1; e. fleet 2; f. fleet 3; g. fleet 4). The dark dotted lines stand for the set of possibilities including the 100 simulated trajectories and the gray fields include $95 \%$ of the latter. The green lines represent the median values of the 100 trajectories. The red dashed lines stand for the viability thresholds. The blue lines correspond to the historical paths between 2006 and 2011. 
(a)
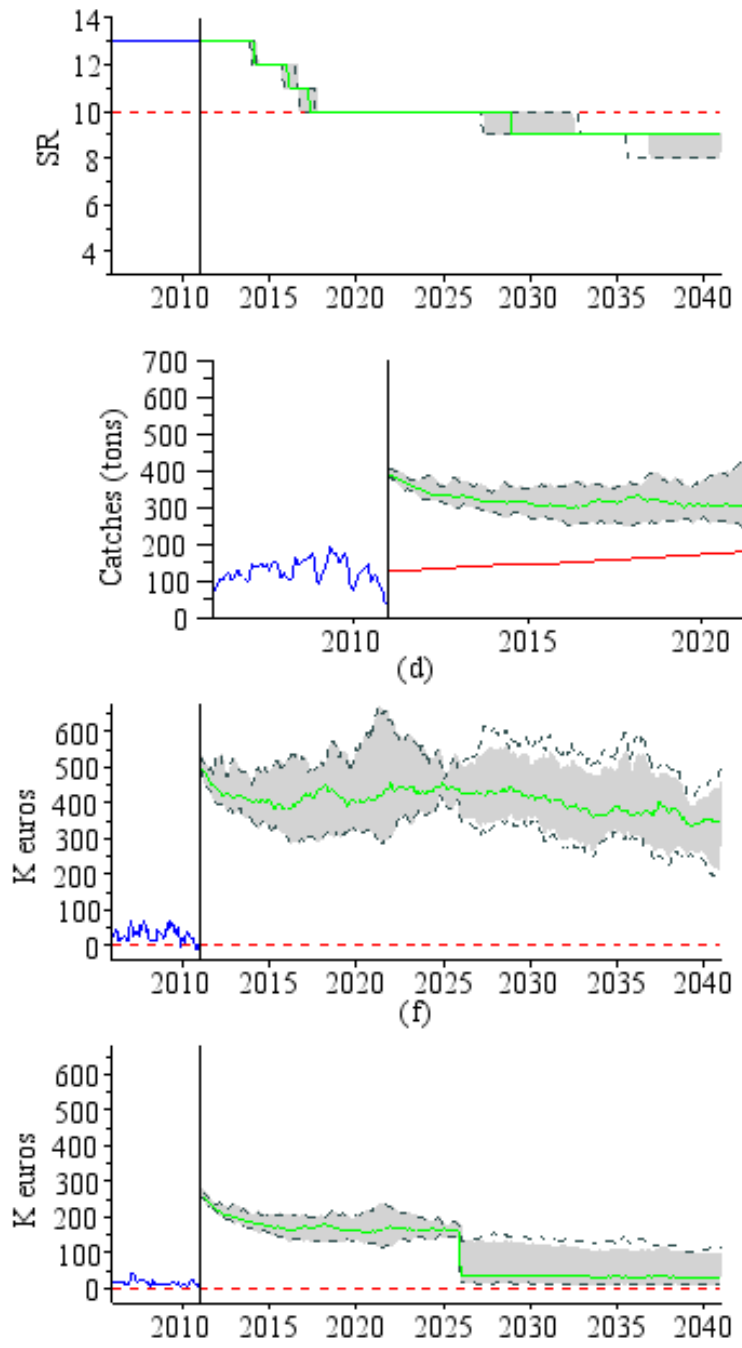

(b)

(c)

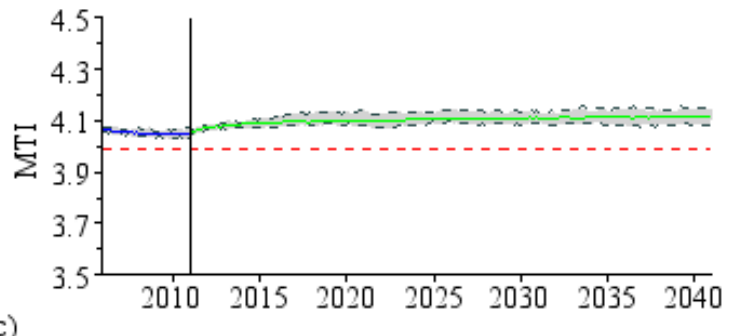

)
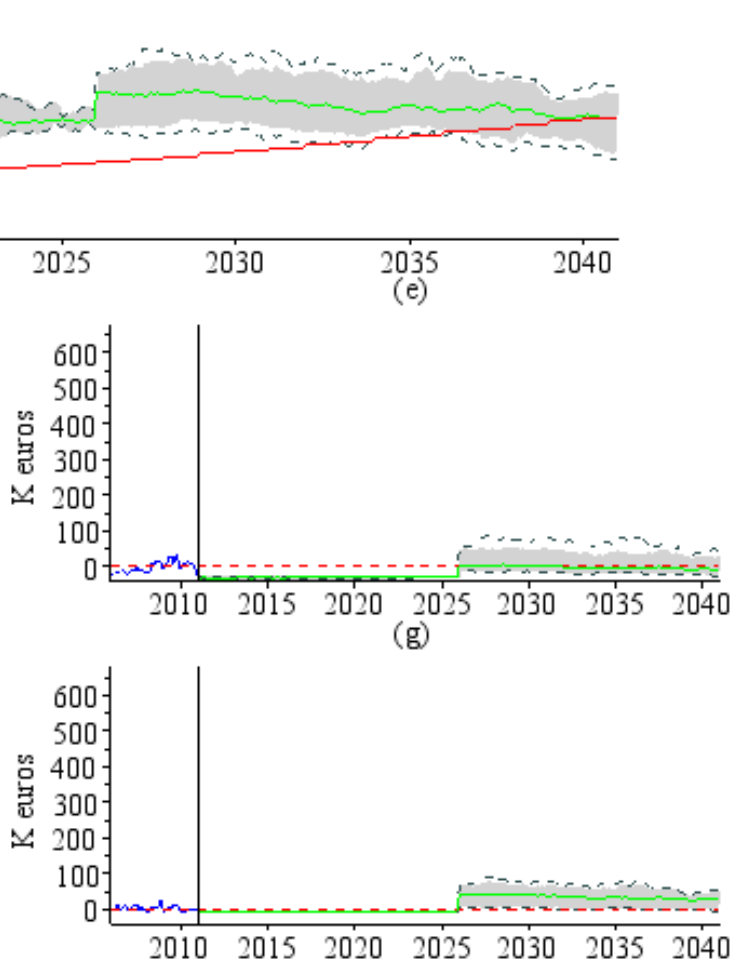

Figure 4: Economic scenario (ECOS) main outputs with $u_{f}^{E C O S}(t)$ : Evolution of the species richness (a), marine trophic index (b), total catches (c) and profits by fleet (d. fleet 1; e. fleet 2; f. fleet 3; g. fleet 4). The dark dotted lines stand for the set of possibilities including the 100 simulated trajectories and the gray fields include $95 \%$ of the latter. The green lines represent the median values of the 100 trajectories. The red dashed lines stand for the viability thresholds. The blue lines correspond to the historical paths between 2006 and 2011. 
(a)
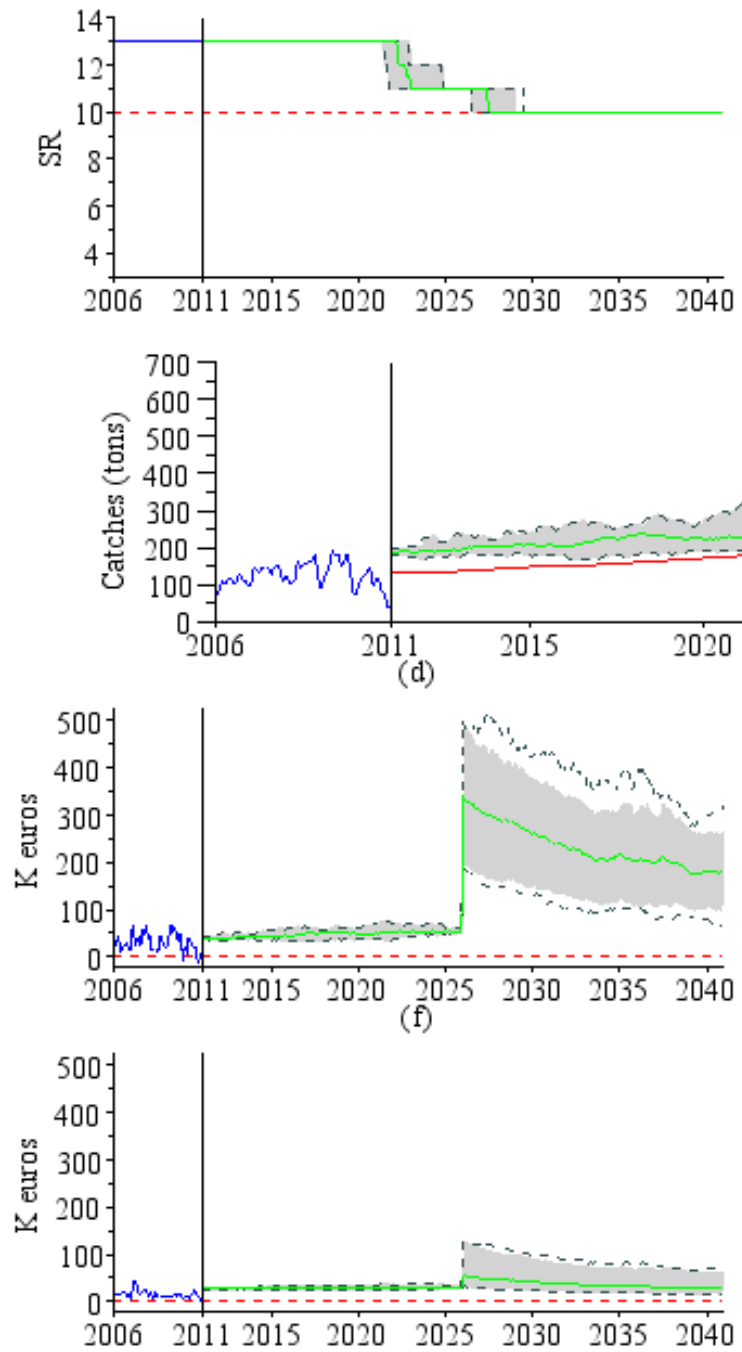

(b)

(c)
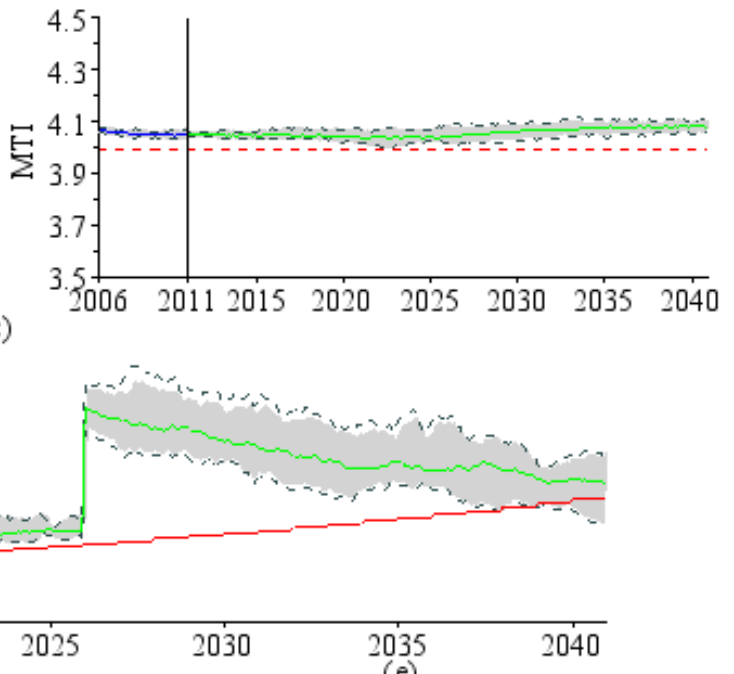

(e)
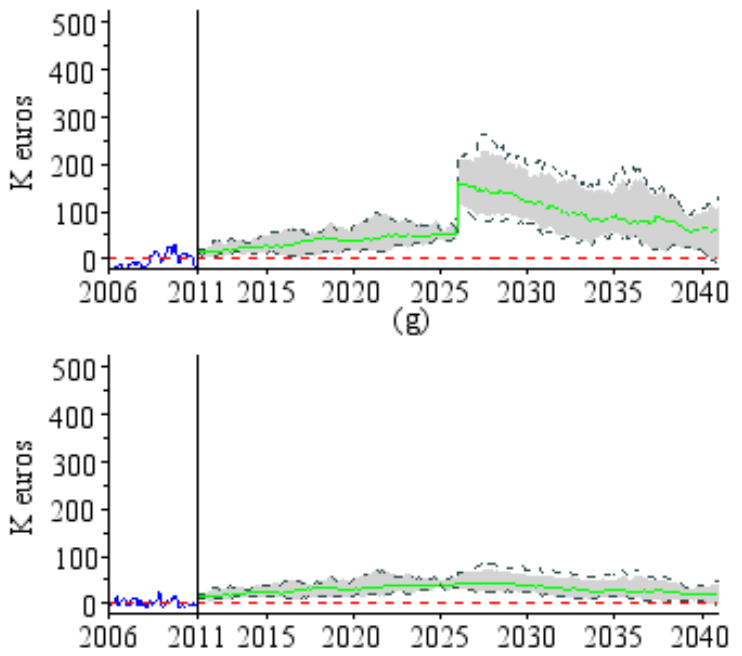

Figure 5: Eco-viability scenario (EVS) main outputs with $u_{f}^{E V S}(t)$ : Evolution of the species richness (a), marine trophic index (b), total catches (c) and profits by fleet (d. fleet 1; e. fleet 2; f. fleet 3; g. fleet 4). The dark dotted lines stand for the set of possibilities including the 100 simulated trajectories and the gray fields include $95 \%$ of the latter. The green lines represent the median values of the 100 trajectories. The red dashed lines stand for the viability thresholds. The blue lines correspond to the historical paths between 2006 and 2011 . 


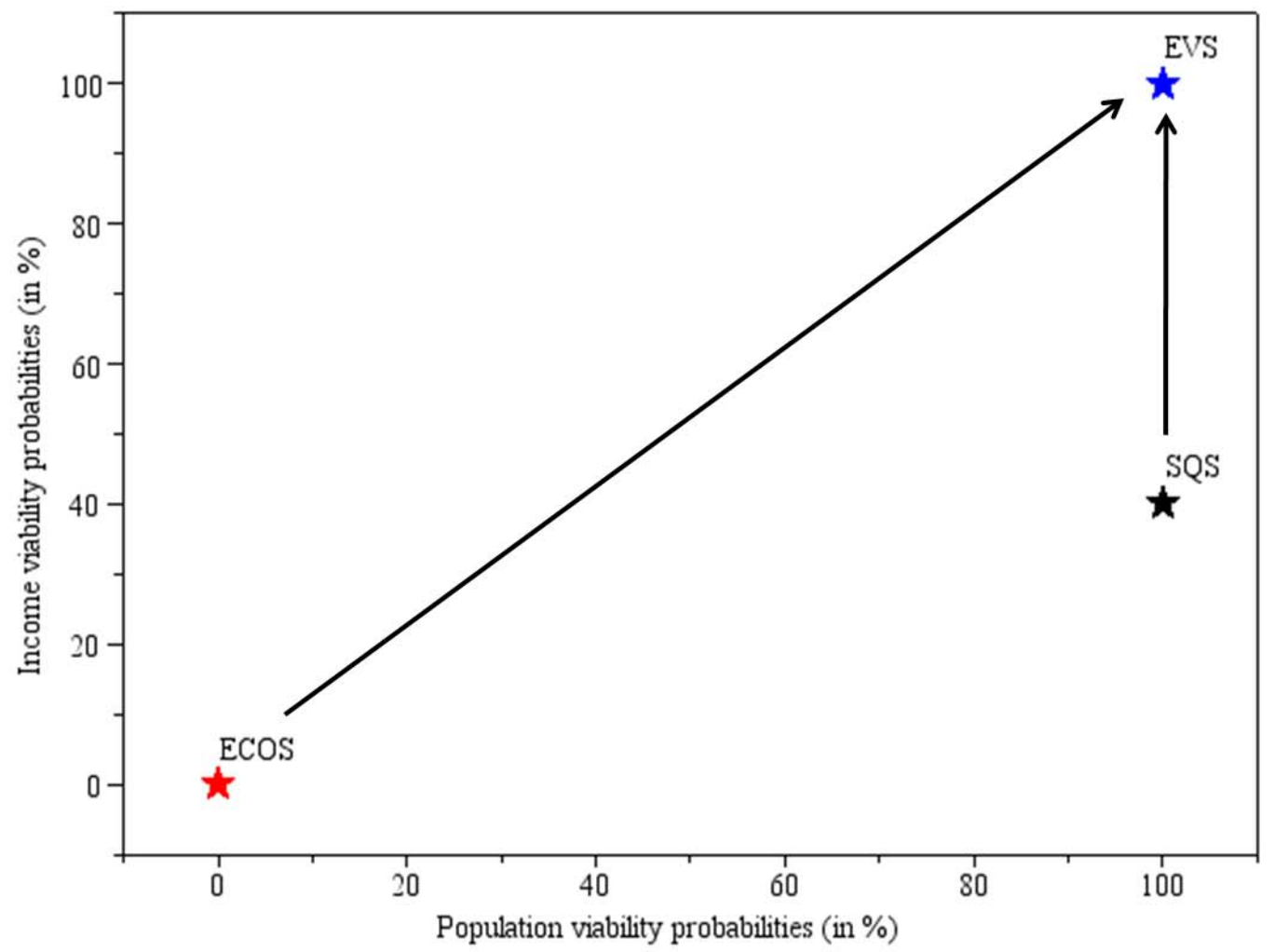

Figure 6: Income viability probabilities (IVP) versus ecological viability probabilities (PVP) for the scenarios SQS, ECOS and EVS. 


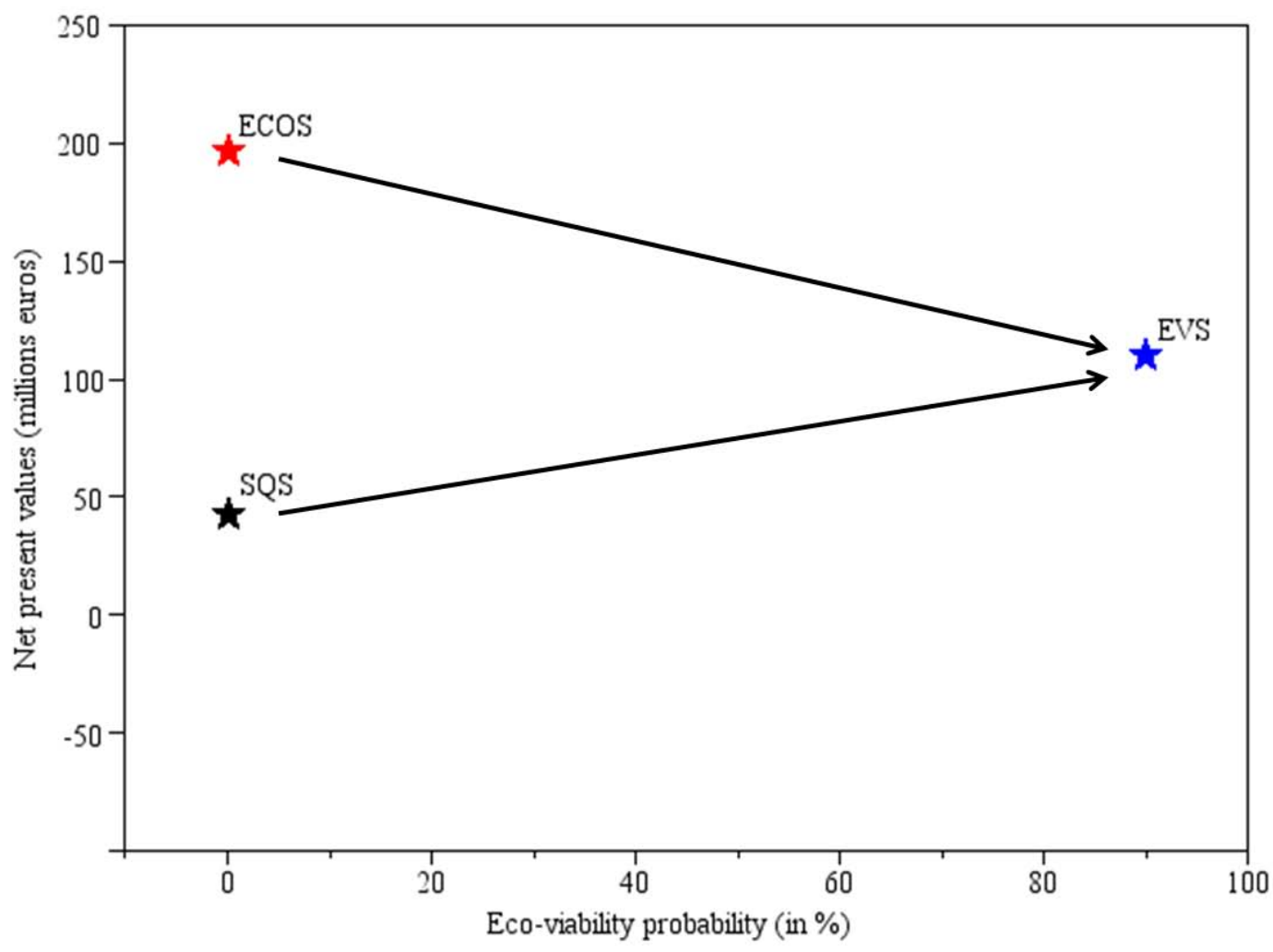

Figure 7: Net present values (NPV) versus eco-viability probabilities (EVP) for the scenarios SQS, ECOS and EVS. 


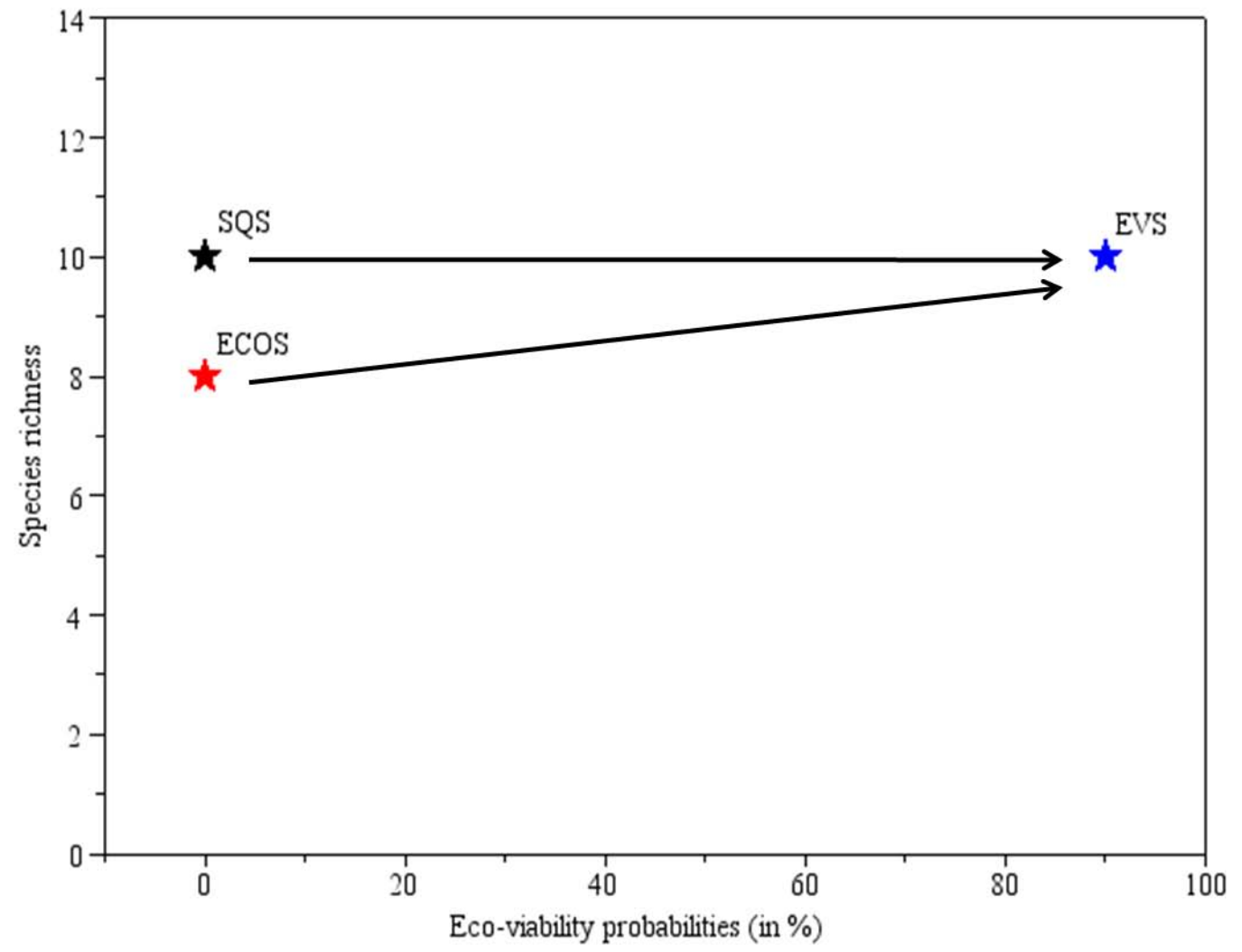

Figure 8: Species richness versus Eco-viability probabilities (EVP) for each scenario. 


\section{Appendix A. Appendix}

Appendix A.1. Details of the numerical computations

This appendix shows the computation of the feedback efforts in the different scenarios based on the associated closed-loop optimization problems. In the ECOS scenario, efforts are solution of the theoretical optimization problem

$$
\max _{e\left(t_{1}\right)} \mathbb{E}_{\epsilon_{1}}\left[\sum_{t=t_{1}}^{t_{2}-1}(1+\gamma)^{t_{1}-t} \pi\left(t, e\left(t_{1}\right), \epsilon_{1}\right)+\max _{e\left(t_{2}, \epsilon_{1}\right)} \mathbb{E}_{\epsilon_{2}} \sum_{t=t_{2}}^{T-1}(1+\gamma)^{t_{2}-t} \pi\left(t, e\left(t_{1}, \epsilon_{1}\right), \epsilon_{2}\right)+\frac{(1+\gamma)^{1-T}}{\gamma} \pi(T)\right]
$$

From a numerical point of view approximating the expected value by the average with respect to the $N^{2}$ replicates (here 100) of $\epsilon$ gives

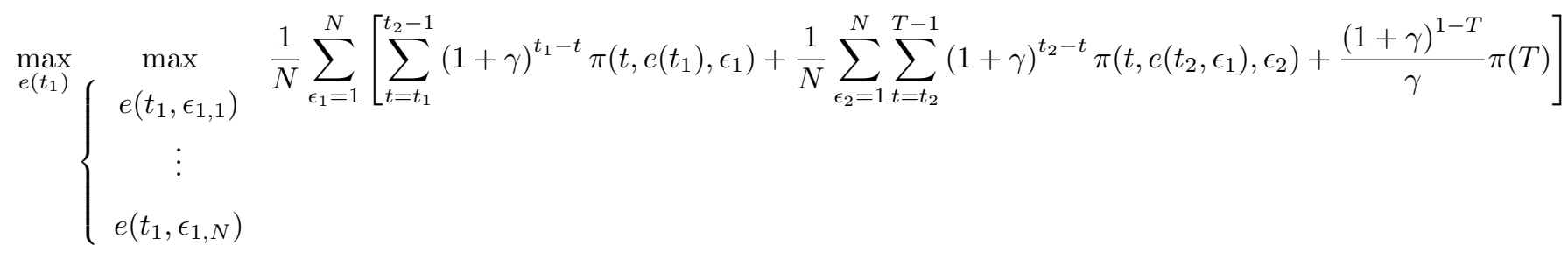

or equivalently

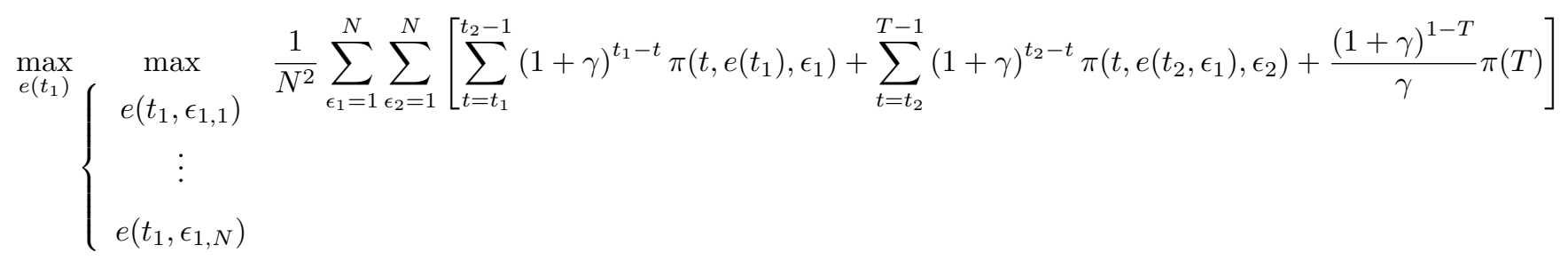

Efforts in the EVS scenario are computed in a similar way using the fact that the probability is the expected value over an indicator function. More specifically, we can rewrite equation (17) as follows

$$
E V P(e)=\mathbb{E}\left[\prod_{t=t_{1}}^{T} \mathbf{1}_{\text {constraints }}(B(t), e(t), \epsilon(t))\right]
$$

using the indicator function.

Let us note that in an open loop model, efforts are solution of the problem

$$
\left\{\begin{array}{l}
\left.\max t_{1}\right) \\
e\left(t_{2}\right)
\end{array} \mathbb{E}_{\epsilon}\left[\sum_{t=t_{1}}^{T-1}(1+\gamma)^{t_{1}-t} \pi(t)+\gamma^{-1}(1+\gamma)^{1-T} \pi(T)\right]\right.
$$




\section{Appendix A.2. Calibration results}

Figure (A.9) presents the historical and simulated catches by fleet. For each fleet $f$ were computed the mean relative errors $\Delta_{f}$, in Euclidean or quadratic norm, between observed and simulated catches from January 2006 to December 2010,

$$
\Delta_{f}^{*}=\sqrt{\frac{1}{60} \sum_{t=t_{0}}^{t_{1}-1}\left(\frac{\left(H_{f}^{\text {data }}(t)-H_{f}(t)\right)}{H_{f}(t)}\right)^{2}}
$$

where $H_{f}(t)=\sum_{i} H_{i, f}(t)$ stands for catches by fleet $f$ at time $t$ over the whole 13 species $i$. The mean relative errors equal $\Delta_{1}^{*}=0.33$ for fleet $1, \Delta_{2}^{*}=0.17$ for fleet $2, \Delta_{3}^{*}=0.40$ for fleet 3 and $\Delta_{4}^{*}=0.32$ for fleet 4.

(a)

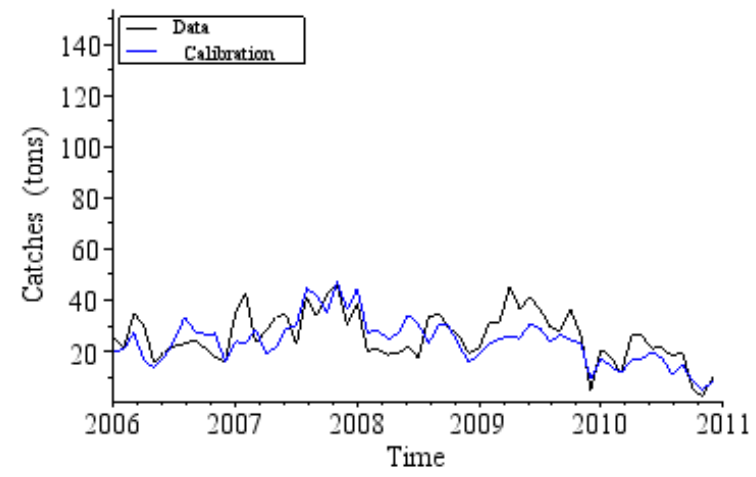

(c)

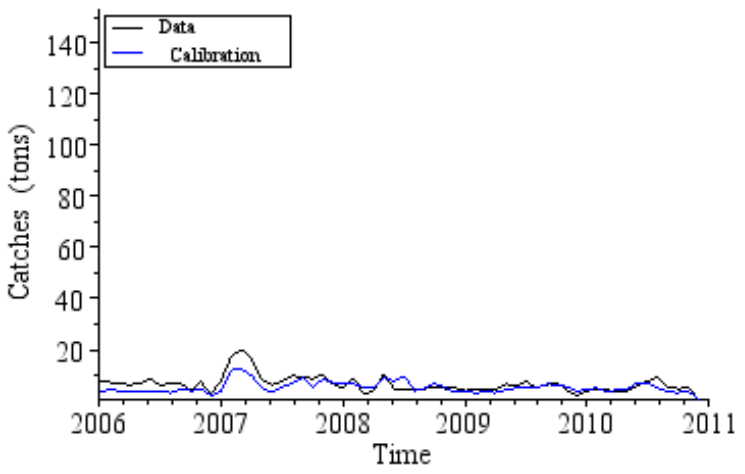

(b)

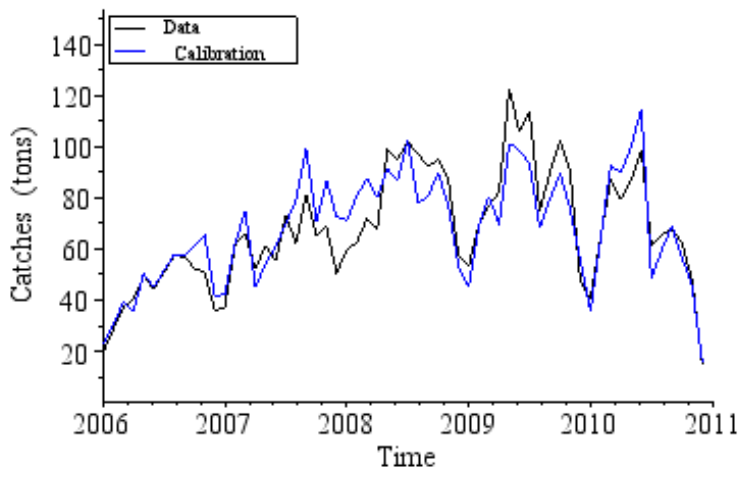

(d)

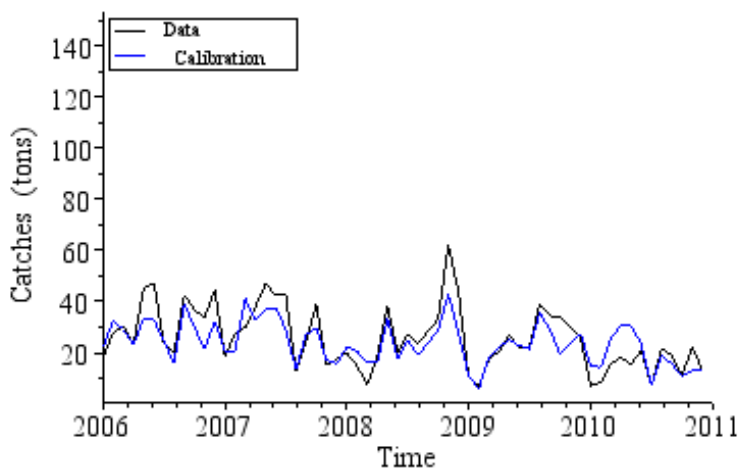

Figure A.9: Comparison by fleet(a. fleet 1 ; b. fleet 2 ; c. fleet 3 ; d. fleet 4$) f$ between historical catches $\sum_{i} H_{i, f}^{\text {data }}(t)$ and simulated catches $\sum_{i} H_{i, f}(t)$. 


\section{Appendix A.3. Details on estimated biological parameters}

Table A.3: Initial stocks, intrinsic growth rates, catchabilities of selected species and uncertainty parameter from calibration.

\begin{tabular}{|c|c|c|c|c|c|c|c|}
\hline $\operatorname{Species}(i)$ & $\begin{array}{c}\text { Initial stocks } \\
\text { (December 2005) } \\
B_{i}(0) \\
(\text { tons })\end{array}$ & $\begin{array}{c}\text { Intrinsic } \\
\text { growth rate }\left(r_{i}\right) \\
(\text { Fisbase }) \\
* 10^{-2}(/ \text { month })\end{array}$ & $\begin{array}{c}\text { Catchability } \\
\text { fleet } f=1 \\
\left(q_{i, 1}\right) \\
* 10^{-7} \text { (/hour) }\end{array}$ & $\begin{array}{c}\text { Catchability } \\
\text { fleet } f=2 \\
\quad\left(q_{i, 2}\right) \\
* 10^{-7}(/ \text { hour })\end{array}$ & $\begin{array}{c}\text { Catchability } \\
\text { fleet } f=3 \\
\left(q_{i, 3}\right) \\
* 10^{-7} \text { (/hour) }\end{array}$ & $\begin{array}{c}\text { Catchability } \\
\text { fleet } f=4 \\
\left(q_{i, 4}\right) \\
* 10^{-7} \text { (/hour) }\end{array}$ & $\begin{array}{c}\text { Uncertainty } \\
\text { parameter } \\
\sigma^{2} \\
(\%)\end{array}$ \\
\hline A. weakfish & 17,358 & 2.08 & 1.04 & 1.76 & 0.33 & 3.85 & 3.01 \\
\hline C. catfish & 15,448 & 5.95 & 1.36 & 0.67 & 0.67 & 0.44 & 3.01 \\
\hline G. weakfish & 7,111 & 0.16 & 1.61 & 1.50 & 0.93 & 3.56 & 3.01 \\
\hline C. snooks & 390 & 4.21 & 14.35 & 8.09 & 10.98 & 1.64 & 3.01 \\
\hline Sharks & 274 & -4.72 & 11.67 & 12.17 & 16.19 & 43.47 & 3.01 \\
\hline S. weakfish & 2,301 & 0.64 & 1.50 & 1.43 & 1.56 & 0. & 3.01 \\
\hline S.croaker & 252 & 3.44 & 6.36 & 4.32 & 7.48 & 0. & 3.01 \\
\hline Tripletail & 476 & 9.34 & 9.72 & 9.29 & 5.28 & 3.01 & 3.01 \\
\hline G. catfish & 93 & 2.59 & 29.89 & 35.19 & 33.80 & 17.22 & 3.01 \\
\hline B. catfish & 214 & 4.21 & 7.92 & 2.65 & 23.39 & 0. & 3.01 \\
\hline G. grouper & 268 & -2.26 & 17.88 & 4.18 & 11.00 & 7.05 & 3.01 \\
\hline F. mullet & 260 & 5.31 & 6.11 & 2.53 & 6.27 & 0. & 3.01 \\
\hline P. mullet & 187 & 7.03 & 9.61 & 1.41 & 15.63 & 0. & 3.01 \\
\hline
\end{tabular}


Table A.4: Trophic relations matrix, $s_{i, j}\left(* 10^{-12} / \mathrm{kg}\right)$ from calibration. Values given are the trophic effect of species $(i)$ on species $(j)$ : positive if $j$ is a prey of $i$ and negative if $j$ is a predator of $i$. The intra-specific interactions $s_{i, i}$ refer to: $s_{i, i}=-r_{i} / K_{i}$

\begin{tabular}{|c|c|c|c|c|c|c|c|c|c|c|c|c|c|}
\hline & A.weak. & C.cat. & G. weak. & C. snoo. & Sharks & S.weak. & S. croa. & Triple. & G. cat. & B. cat. & G.grou. & F. mul. & P. mul. \\
\hline A.weak. & -330.20 & 1.0D-09 & $-9.2 \mathrm{D}-04$ & $1.1 \mathrm{D}-04$ & $-8.2 \mathrm{D}-09$ & $-8.5 \mathrm{D}-10$ & $2.1 \mathrm{D}-04$ & $2.4 \mathrm{D}-04$ & - 4.2D-09 & $1.8 \mathrm{D}-04$ & $-4.2 \mathrm{D}-09$ & 1.1D-09 & $1.0 \mathrm{D}-09$ \\
\hline C.cat. & - 8.1D-09 & - 4066.7 & $-8.3 \mathrm{D}-04$ & $-6.3 \mathrm{D}-09$ & - 4.7D-09 & - 1.0D-03 & - 8.1D-09 & - 1.1D-03 & - 5.2D-09 & $8.7 \mathrm{D}-10$ & $-5.3 \mathrm{D}-04$ & $1.8 \mathrm{D}-04$ & $2.6 \mathrm{D}-04$ \\
\hline G. weak. & $1.1 \mathrm{D}-04$ & $1.0 \mathrm{D}-04$ & -56.8 & $1.5 \mathrm{D}-09$ & - 5.0D-09 & $-2.3 \mathrm{D}-09$ & $1.7 \mathrm{D}-09$ & 1.0D-09 & - 8.7D-04 & $1.2 \mathrm{D}-09$ & - 6.0D-09 & $1.2 \mathrm{D}-04$ & $1.0 \mathrm{D}-09$ \\
\hline C. snoo. & $-9.40-04$ & - 1.0D-08 & $-1.2 \mathrm{D}-08$ & -14602.2 & - 7.7D-04 & $-4.4 \mathrm{D}-09$ & $-1.1 \mathrm{D}-03$ & - 5.3D-09 & - 9.3D-04 & $1.1 \mathrm{D}-04$ & $-5.3 \mathrm{D}-04$ & $5.6 \mathrm{D}-05$ & 4.7D-05 \\
\hline Sharks & 1.0D-09 & $5.8 \mathrm{D}-10$ & $6.2 \mathrm{D}-10$ & $9.6 \mathrm{D}-05$ & -12439.5 & 8.7D-05 & 3.1D-04 & $2.1 \mathrm{D}-04$ & $9.5 \mathrm{D}-10$ & $9.4 \mathrm{D}-10$ & $-4.4 \mathrm{D}-04$ & $1.3 \mathrm{D}-04$ & $1.2 \mathrm{D}-09$ \\
\hline S.weak. & $-1.5 \mathrm{D}-08$ & $1.2 \mathrm{D}-04$ & $-5.6 \mathrm{D}-09$ & $5.5 \mathrm{D}-10$ & $-6.9 \mathrm{D}-04$ & -690.4 & $1.3 \mathrm{D}-09$ & $1.5 \mathrm{D}-04$ & - 9.9D-04 & 1.0D-09 & - 7.7D-09 & $2.0 \mathrm{D}-04$ & 4.1D-10 \\
\hline S. croa. & $-1.7 \mathrm{D}-03$ & $-3.3 D-09$ & $-1.4 \mathrm{D}-08$ & $1.3 \mathrm{D}-04$ & $-2.5 \mathrm{D}-03$ & $-1.1 \mathrm{D}-08$ & -41463.6 & - 3.0D-09 & - 4.8D-09 & $1.3 \mathrm{D}-09$ & $-2.6 \mathrm{D}-04$ & $1.0 \mathrm{D}-09$ & $2.9 \mathrm{D}-04$ \\
\hline Triple. & $-1.9 \mathrm{D}-03$ & $-1.1 \mathrm{D}-03$ & - 8.0D-09 & $-3.3 D-09$ & - 1.7D-03 & $-1.2 \mathrm{D}-03$ & - 6.7D-09 & - 183356.2 & - 5.4D-09 & $6.8 \mathrm{D}-05$ & - 3.3D-09 & $5.7 \mathrm{D}-10$ & 7.3D-05 \\
\hline G. cat. & $5.3 \mathrm{D}-10$ & $6.6 \mathrm{D}-10$ & 1.0D-04 & $1.1 \mathrm{D}-04$ & $-7.6 \mathrm{D}-09$ & $1.2 \mathrm{D}-04$ & $6.0 \mathrm{D}-10$ & $6.8 \mathrm{D}-10$ & -57697.8 & $5.3 \mathrm{D}-05$ & $-4.8 \mathrm{D}-09$ & $1.5 \mathrm{D}-04$ & $8.4 \mathrm{D}-10$ \\
\hline B. cat. & $-1.4 \mathrm{D}-03$ & - 7.0D-09 & - 1.0D-08 & $-9.4 \mathrm{D}-04$ & - 7.5D-09 & $-8.2 \mathrm{D}-09$ & $-1.0 \mathrm{D}-08$ & - 5.5D-04 & $-4.2 \mathrm{D}-04$ & - 180203.8 & - 4.9D-09 & 0. & 0. \\
\hline G.grou. & $5.2 \mathrm{D}-10$ & 6.7D-05 & $7.5 \mathrm{D}-10$ & $6.7 \mathrm{D}-05$ & $-1.5 \mathrm{D}-03$ & $9.6 \mathrm{D}-10$ & 3.2D-05 & $4.1 \mathrm{D}-10$ & $6.0 \mathrm{D}-10$ & $6.1 \mathrm{D}-10$ & -16485.4 & $5.8 \mathrm{D}-10$ & $1.2 \mathrm{D}-09$ \\
\hline F. mul. & $-8.8 \mathrm{D}-09$ & $-1.5 \mathrm{D}-03$ & - 1.0D-03 & $-4.4 \mathrm{D}-04$ & - 1.0D-03 & $-1.6 \mathrm{D}-03$ & - 8.0D-09 & - 4.6D-09 & $-1.2 \mathrm{D}-03$ & 0. & - 4.7D-09 & - 169046.3 & 0. \\
\hline P. mul. & $-8.4 \mathrm{D}-09$ & - 2.0D-03 & $-8.2 \mathrm{D}-09$ & $-3.7 \mathrm{D}-04$ & $-1.0 \mathrm{D}-08$ & $-3.2 \mathrm{D}-09$ & $-2.3 \mathrm{D}-03$ & $-5.8 \mathrm{D}-04$ & - 6.7D-09 & 0. & - 9.9D-09 & 0. & -310836.5 \\
\hline
\end{tabular}




\section{Appendix A.4. Economic data}

Table A.5: 2010 economic data (variable costs, fixed costs and selling prices).

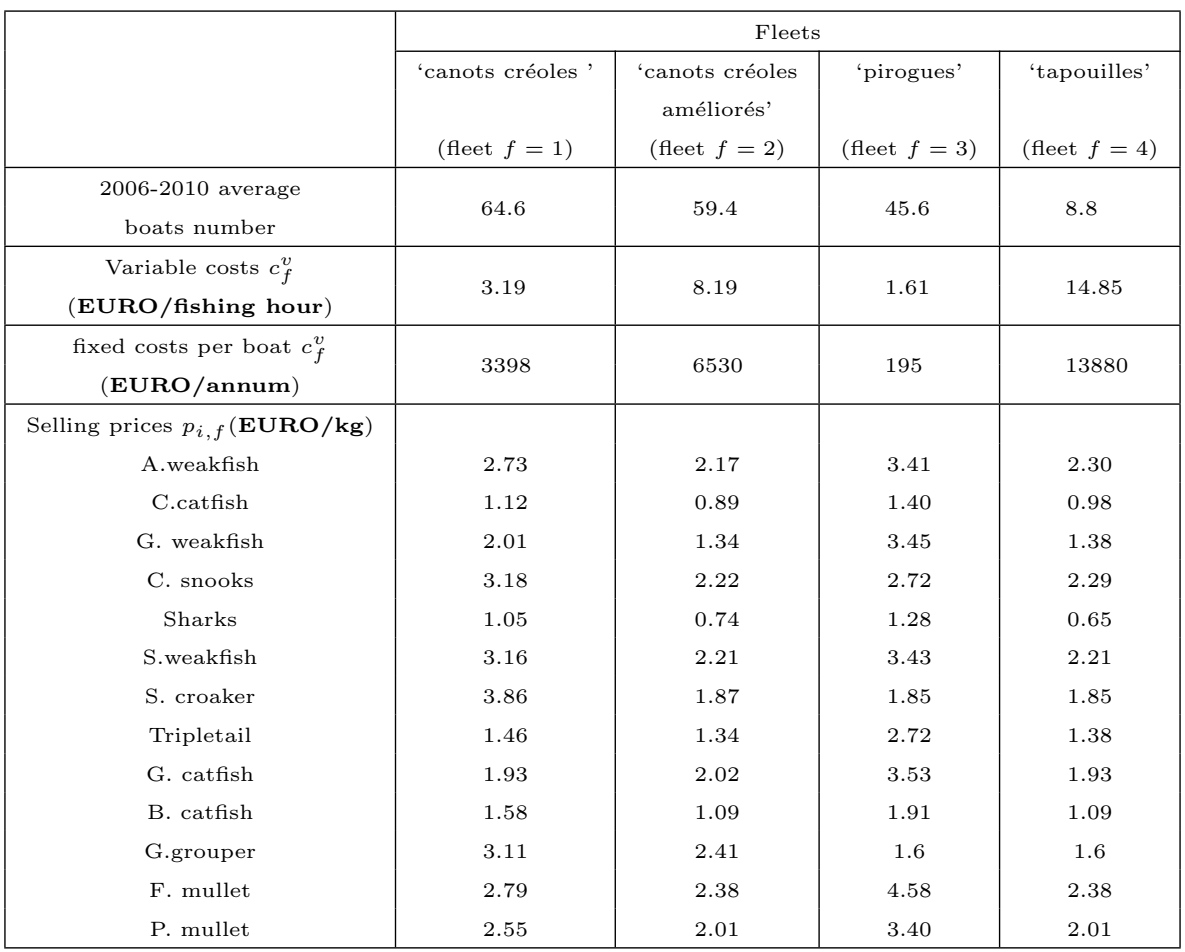

